\title{
Parallels in invasion and angiogenesis provide pivotal points for therapeutic intervention
}

\author{
SUZANNE A. ECCLES* \\ Institute of Cancer Research, Sutton, U.K.
}

\begin{abstract}
Biological evolution is economical and successful fundamental processes are frequently recapitulated. There are remarkable similarities in the molecular mechanisms which enable tumour cells to invade into surrounding tissues and activated endothelial cells to generate new capillaries, which facilitate the growth and dissemination of cancer. Indeed these pathological processes are themselves based upon key vertebrate developmental processes, and in some cases parallel strategies used by microorganisms to colonise their hosts' tissues. The aim of this review is to explore these parallels in more detail and indicate possible pivotal points for therapeutic intervention. These novel approaches may ultimately optimise the selective targeting of processes involved in tumour invasion and angiogenesis, while sparing normal adult proliferating tissues. Strategies include inhibition of oncogenic pathways in tumour cells which not only stimulate tumour cell growth and invasion, but also initiate neoangiogenesis by upregulation of angiogenic cytokines. Secondly, downstream signalling pathways, transcriptional regulation and effectors common to both processes, and finally points of interaction/cross-talk between tumour cells and endothelial cells which are necessary to enable invasion and angiogenesis to proceed.
\end{abstract}

KEY WORDS: motility, proteolysis, signalling, angiogenesis, invasion

\section{Parallels in invasion and angiogenesis}

Taking a reductionist approach, we can consider that both tumour invasion and capillary sprouting require that cells successfully manage the following challenges: survival in ectopic environments where normal anti-apoptotic signals may be lacking; overcoming the "default" position of quiescence in adult differentiated cells $\left(\mathrm{G}_{0}\right)$ and activation of proliferation; modification of adhesive interactions with the extracellular matrix and surrounding cells enabling tissue plasticity; acquisition of migratory capacity and ability to respond to chemokine gradients and other soluble or immobilised motility factors; degradation of extracellular matrix to release latent growth factors and provide a conduit for expansion into the surrounding tissues; response to the new microenvironment to achieve colonisation or differentiation.

These imperatives can be explored at the cellular level, but ultimately key molecules must be identified which might serve as targets for therapy (Table 1). In view of the "multigenic" nature of tumour progression and probable redundancy of effectors, benefit may be obtained by seeking "nodal points" which are rate limiting for a particular process and ideally which are common to both invasion and angiogenesis. Therapeutic strategies have considered every level from cell surface receptors to transcription factors; all have advantages and disadvantages (Fig. 1).

Interactions between tumour and host cells during angiogenesis and invasion

There are many examples of two-way communications between tumour and host cells which may yield points for therapeutic intervention and indeed targeting the host side of the equation may

Abbreviations used in this paper:ADAM, adamalysin related membrane protease; APC, adenomatous polyposis coli; BM, basement membrane; BTC, betacellulin; COX-2, cyclo-oxygenase 2; FAK, focal adhesion kinase; FAP, familial adenomatous polyposis; $\mathrm{FGF}(\mathrm{R})$, fibroblast growth factor (receptor); GSK3, glycogen synthase kinase 3; HGF, hepatocyte growth factor; HIF, hypoxia inducible factor; HRG, heregulin; IL, interleukin; ILK, integrin linked kinase; iNOS, inducible nitric oxide synthase; MAPK, mitogen activated kinase; MIF, migration inhibitory factor; MMP, matrix metalloprotease; NSAID, non-steroidal anti-inflammatory drug; OPN, osteopontin; PAI-1, plasminogen activator inhibitor; PGE, prostaglandin E; PI3K, phosphatidylinositol 3 kinase; PTEN, phosphatase and tensin homologue; RTK, receptor tyrosine kinase; TGF $\alpha(\beta)(\mathrm{R})$, transforming growth factor $\alpha(\beta)$ (receptor); uPA $(\mathrm{R})$, urokinase plasminogen activator (receptor); VEGF, vascular endothelial growth factor; VHL, von Hippel Lindau.

*Address correspondence to: Dr. Suzanne A. Eccles. Cancer Research UK Centre for Cancer Therapeutics, McElwain Laboratories, Institute of Cancer Research, Cotswold Rd, Belmont, Sutton, Surrey, SM2 5NG, U.K. Fax: +44-20-8722-4134. e-mail: sue.eccles@icr.ac.uk 
beless likely to induce drug resistance. Many proteases overexpressed in tumours are stromal in origin, inflammatory cells (or the malignant cells themselves) produce angiogenic cytokines and motility factors which activate endothelial and/or tumour cells. (Fig. 2).

There are also key cell-cell adhesive and ligand-receptor interactions which impact on tumour cell extravasation and organ colonisation patterns. During tumour cell extravasation, transient adhesive interactions mediated primarily by endothelial $(E)$-selectins and their ligands on tumour cells activate multiple pathways involving cytokines, bioactive lipids and growth factors, similar to processes involved in vascular damage. Subsequent engagement of integrin signalling pathways ensures that the anti-apoptotic machinery is enabled and proteolytic and chemotactic activity induced. Blocking critical binding sites between ECM components that interact with invasive tumour cells and activated endothelia may provide a new therapeutic approach (Sanz, 2003)

Following extravasation, regulation of growth of disseminated cells at secondary sites is a major determinant of metastatic efficiency. This may be achieved via sensitivity to local chemokines and growth factors, the ability to induce neoangiogenesis and/or cooption of existing vessels in this environment. For example c-MAF, a key oncogene in myeloma potentiates survival of the cells in bone marrow by enhancing their interaction with the stroma via integrin $\beta 7$ and E-cadherin and by concomitantly upregulating VEGF, a potent angiogenic cytokine (Hurt, 2004).

\section{Tumour neoangiogenesis: a necessary prerequisite for metastasis?}

The major angiogenic cytokines produced in tumours via oncogene activation and/or hypoxia are the VEGF family. VEGF-A binds to receptors on endothelial cells, VEGFR-1 (Flt-1) and VEGFR-2 (Flk1/KDR) (Rakic, 2003a). VEGF-C and D act as specific lymphangiogenic cytokines, since they activate VEGFR-3 (Flt-4) preferentially expressed on lymphatic endothelia. VEGFs, in addition to acting as potent survival factors also enhance vessel permeability, thus increasing the opportunity for both vascular and lymphatic invasion and tumour spread.

VEGF-R signaling through Ras-ERK1/2 MAPK, PLC $\gamma$ and PI3 kinase pathways collectively contributes to cell survival, proliferation, migration and differentiation. Activated endothelial cells also produce proteolytic enzymes including urokinase-type plasminogen

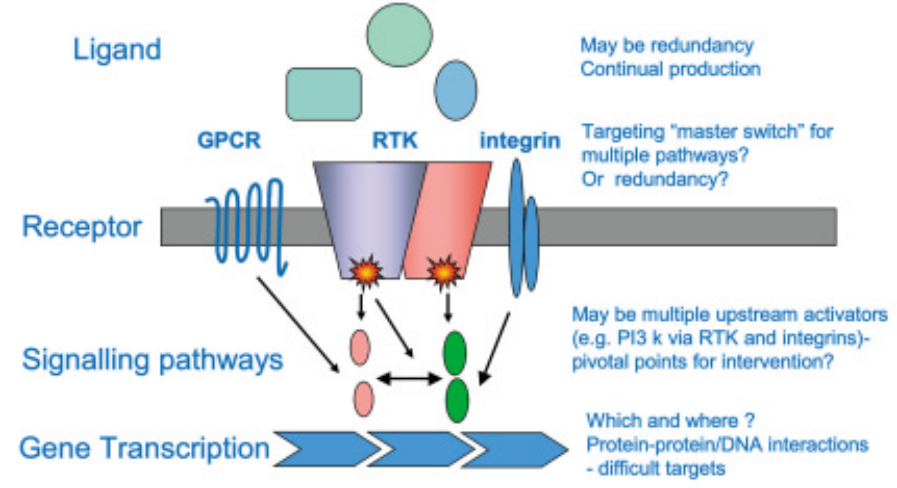

Fig. 1. Potential points for therapeutic intervention. Different "levels" from cell surface receptors to transcription factors are considered with their pros and cons as generic therapeutic targets.

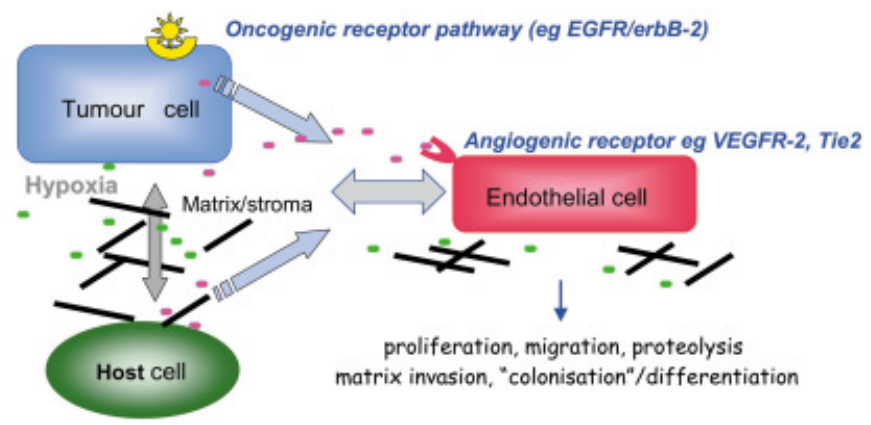

Production and release of angiogenic INVASION/ANGIOGENESIS factors and proteases

Fig. 2. Tumour-host interactions in invasion and angiogenesis. Tumour angiogenesis and metastasis require the functional integration of multiple signalling circuits in tumour and host cells. "Induction" involves the production, stabilisation and release of effector molecules; the "response" element involves downstream signalling pathways in effector cells driving key functions involved in both processes, i.e. proliferation, motility, proteolysis, ECM invasion and "colonisation" of new sites (establishment of micrometastasis or capillary differentiation).

activator (uPA) (Rakic, 2003b) and matrix metalloproteinases (MMPs) to degrade the surrounding extracellular matrix (ECM), allowing directional migration towards angiogenic stimuli. Endothelial cells then differentiate to form tubular structures; finally recruiting supporting cells to stabilize the newly formed vessels. Inhibitors of many of these processes are being explored as adjuncts to conventional cancer therapy, sparing normal tissues in which endothelial cells are generally quiescent and potentially limiting both tumour growth and dissemination.

Some particularly aggressive tumours (e.g. melanomas) show "vasculogenic mimicry" and form channels capable of transporting blood without recruiting endothelial cells. (Maniotis, 1999). Such cells express "endothelial" proteins including VE-cadherin and Eph-2a and hence may be susceptible to therapies that target these molecules and their signalling pathways. As will be discussed later, several "antiangiogenic" agents are also anti-invasive and vice versa.

\section{Induction of invasion and angiogenesis: molecular triggers}

Various "drivers" of tumour initiation and progression have been identified and in many cases are capable of concurrently potentiating invasion and angiogenesis. These include certain pathogens, loss of tumour suppressor genes such as APC, PTEN and p53, mutated or over-expressed peptide- or steroid growth factor receptors, activated signalling pathways and their downstream effectors. These all have the potential to provide rational points for therapeutic intervention which may be expected to have pleiotropic effects. The next sections will consider the underlying molecular mechanisms and discuss attempts to exploit them as therapeutic targets.

\section{Pathogens}

H. Pyloriinfection is a key risk factor in gastric carcinoma. Coculture with gastric carcinoma cells induced IL-8, VEGF, UPA, MMP-9 and angiogenin (Kitadai 2003), major players in angiogenesis and invasion. Listeria monocytogenes stimulates invasion of 
colon cancer cells via a 13 mer casein-derived peptide involving Cdc42 and inactivation of RhoA and PI3 kinase, again suggesting that enteric bacteria may promote tumour progression (Oliveira 2003). Human herpes virus 8 and HIV-1 are implicated in haemangiomas and Kaposi's sarcoma. HIV-1 tat protein activates VEGFR-2, binds endothelial $\alpha 5 \beta 1$ and $\alpha \mathrm{V} \beta 3$ integrins and releases FGF2 from the ECM. Other viruses such as HPV-16 (implicated in cervical carcinoma) subvert p53 function and their E6 oncoprotein can also activate VEGF in a p53 independent manner. Their mechanisms of action have provided insights into generic processes involved in tumour initiation and progression and identified angiogenesis and invasive potential as early events in oncogenesis.

\section{Loss of tumour suppressors}

\section{$A P C$}

Familial adenomatous polyposis coli (FAP) is associated with mutations in the APC gene and all sporadic colon carcinomas show defects in this and/or the associated E-cadherin-wnt- $\beta$-catenin signalling pathway. In normal cells, $\beta$-catenin is sequestered in $\mathrm{E}$ cadherin adherens junctions, whereas free $\beta$-catenin is phosphorylated by GSK3 $\beta$ and degraded. If the APC tumour suppressor is inactive (via loss or mutation) or GSK3 $\beta$ activity is blocked by wnt signalling, $\beta$-catenin levels increase and translocate to the nucleus where the TCF-LEF-1 transcription complex is activated. These changes also activate Rho family GTPases, leading to a motile, invasive phenotype (Cavallero 2004).

Wnt ligands (Wnt-2, $-5 \mathrm{a},-7 \mathrm{a}$ and -10) and receptors (Fz-1, -2, -3 and -5 ) have been identified in endothelial cells and their loss has been associated with vascular developmental abnormalities.

\section{TABLE 1}

\section{POSSIBLE THERAPEUTIC STRATEGIES FOR TARGETING TU- MOUR ANGIOGENESIS AND INVASION}

\begin{abstract}
Strategy
Inhibit induction of angiogenesis and invasion by targeting RTKs or oncogenes whose activation induces angiogenic cytokines and/or proteolytic enzymes

Target hypoxic environment which potentiates invasion and angiogenesis

Reactivate (or replace function of) suppressor genes lost in cancers whose activity can inhibit invasion/angiogenesis

Inhibit interactions between tumour cells and endothelial cells/stroma during dissemination and growth at secondary sites

Inhibit activity of proteolytic enzymes which potentiate invasion and capillary sprout formation, or release growth factors from stroma

Inhibit signalling pathways implicated in cell survival and/ or motility

Inhibit signalling pathways implicated in cell migration and chemotaxis
\end{abstract}

Inhibit factors permitting growth at secondary sites

Inhibit regulators of multiple transcriptional or signalling events involved in tumour progression
(Goodwin 2002). Interestingly, the natural angiogenesis inhibitor endostatin has been reported to inhibit the $\mathrm{Wnt} / \beta$ catenin pathway in endothelial cells, putatively by regulating $\beta$ catenin stability via a novel GSK3-independent mechanism.

There is a direct correlation between APC mutational status (activation of $\beta$-catenin signalling) and VEGF-A upregulation. Treatment with antisense $\beta$-catenin significantly reduced VEGF-A expression (Easwaran 2003). Since it is well established that activation of this pathway also potentiates invasion, this provides another example of bimodal activation of these two key processes in tumour progression. In clinical colorectal cancer samples, upregulation of VEGF-A and MMP-7 expression occurred simultaneously between stages Tis and T1, suggesting that the "angiogenic switch" and initiation of invasion were concurrent, early events. (Takahashi 2003).

\section{P53 and PTEN}

Loss of p53 function, which occurs in the majority of tumours, leads to the downregulation of the angiogenesis inhibitor thrombospondin 1. Both p53 and the von Hippel-Lindau (VHL) protein target the hypoxia-regulated HIF- $1 \alpha$ for degradation via the proteasome, hence their inactivation increases its lifespan and thus the induction of angiogenic and invasion-promoting genes. Reactivation of p53 function (at least in cancers which retain a wild type allele) by releasing it from the negative control of mdm-2 by cis-imidazoline analogues has shown significant inhibition of tumour xenografts (Vassilev, 2004).

In glioma, acquisition of invasive potential is associated with elevated expression of genes involved in motility and apoptosis resistance - presumably aiding survival in "ectopic" environments. This has been linked to loss of p53 and induction of an "invasion" expression profile (including genes such as thromboxane synthase, MMP-9 etc) mediated via the Ets transcription factor (Kim 2003).

Inactivation of PTEN is almost as common as loss of p53 function and this leads to upregulation of two key signalling pathways, PLC $\gamma$ and PI3 kinase. PI3 kinase is critically important in cell survival and angiogenesis (see below) and both PI3K and PLC $\gamma$ are implicated in cell motility. PTEN loss in prostate cancer also increases HIF-1 $\alpha$ expression, thereby contributing to activation of pro-invasive and pro-angiogenic genes.

\section{Activation of receptor tyrosine kinases (RTK)}

Many genetic changes associated with malignant progression (mutation of $\mathrm{H}$-ras, over-expression of $c$-erbB oncogenes, loss of p53) induce an angiogenic phenotype via upregulation of cytokines such as VEGF-A, FGF2 and IL8. Induction of VEGF-A may be secondary to activation of HIF- $1 \alpha$, either by inhibiting its ubiquitination and degradation, or by increasing its rate of synthesis in a PI3 kinase/MAPK dependent manner. However, activation of EGFR and other oncogenic signalling pathways can also upregulate VEGF-C which is HIF-1 independent (O-charoenrat, 2000). Oncogenic kinase signalling is recognised as a significant area for development of novel cancer therapeutics.

\section{EGFR/c-erbB family}

Epidermal growth factor receptor (EGFR/erbB1), erbB-2 and to a lesser extent erbB-3 and -4 are over expressed in many cancers and collectively trigger multiple downstream signalling cascades. Receptor activation impacts on neoangiogenesis and tumour cell 
dissemination at several levels, including the release of angiogenic factors, motogens and proteases; activation of endothelial cell responses and enhancement of interactions between tumour and endothelial cells. EGF, TGF $\alpha$ and betacellulin (a pan erbB ligand) potently induce MMPs and VEGFs in tumour cellsand can also directly activate MAPK and PI3K pathways in endothelial cells. (reviewed in Eccles 2001, O-charoenrat 2002a, Holbro 2003, Jorissen, 2003).

Heregulin (HRG) $\beta-1$ upregulates transcription of VEGF-A isoforms via a PI3 kinase-Pak-1, MAP/ERK pathwayand/or p38MAPK pathway depending on the cell type. VEGF upregulation is inhibited by antagonistic mabs to EGFR, erbB-2 and erbB-3 receptors, confirming the importance of heterodimers in initiating signal transduction. This is evident not only in pro-angiogenic signaling, but also in tumour cell motility, since EGFR-erbB-2 heterodimers are implicated in transendothelial invasion. Activated erbB oncogenes potentiate tumour cell adhesion to microvessel endothelial cells and induce endothelial cell retraction from the underlying matrix. This process may be linked to erbB-2 induced upregulation of angiopoetin-2 which has been associated with initiation of angiogenesis and induction of proteases including MMP-1, MMP-9 and UPA.

Tumours derived from HRG transgenic mice have increased Pak1 kinase activity, upregulated VEGF and high microvessel density. HRG can also interact directly with erbB receptors on endothelial cells, promoting migration and tube formation in vitro and angiogenesis in vivo. This parallels the motogenic potential of activated erbB-2 (and EGFR) in tumour cells, where it is localized in podosomes and microvilli.

Receptor tyrosine kinase antagonists such as monoclonal antibodies (e.g. Cetuximab, Herceptin,) or kinase inhibitors (e.g. Iressa, Tarceva) may thus have both direct (anti-tumour - effects on proliferation, invasion) and indirect (anti-angiogenic) effectsand these have been well described in many systems (Mendelsohn 2003). A bispecific antibody targeting EGFR and IGF1-R is under development and has been shown to completely block activation of several major signaling pathways, whereas mono-specific antibodies did not. Antibodies and drugs with dual erbB-2/EGFR or VEGFR/EGFR specificity are also being investigated in the hope that they may have additional potency in tumour cells expressing multiple receptors and/or may simultaneously target activated endothelial cells. A combination of orally active EGFR antagonist (Iressa) COX-2 inhibitor (SC-236) and a PKA1 antisense oligonucleotide showed co-operative effects against colon cancer xenografts with significant downregulation of VEGF, FGF2 and angiogenesis (Tortora 2003).

\section{Met}

The Met receptor and its ligand HGF or "scatter factor" are often overexpressed on invasive cancer cells and activated endothelial cells (Ma 2003). Expression levels often correlate with poor prognosis and it is a predictor of invasion and lymph node metastasis in colon cancer. Met activation phosphorylates FAK and couples it to the Ras-MAPK and PI3K-Akt pathways. It has been implicated in epithelial and endothelial cell motility, invasion and branching morphogenesis (Birchmeier 2003). In common with other RTKs, its activation has also been linked to upregulation of angiogenic cytokines (VEGF and IL-8) and COX-2 (Sengupta 2003). Recent data suggest that Met can also interact with Src, PLC $\gamma$, CD44, integrins, ezrin, paxillin, semaphorin receptors and E-cadherin, all key players in cell motility and invasion.

There is thus compelling evidence of a role for Met signaling in tumour invasion and angiogenesis and several inhibitors are in development. Ribozymes and siRNA have been shown to inhibit xenograft growth and angiogenesis. Infection of PC3-LN4 prostate carcinoma cells with adenoviral vectors carrying Met ribozymes decreased Met levels, Src kinase activity and VEGF-A and IL-8 production. Responses included reduced in vitro invasion and in vivo lymphatic metastasis (Kim 2003).

Antibodies targeting Met or its ligand have shown promise in vitro and in experimental tumour models. NK-4, an internal fragment of HGF, is a competitive antagonist of the Met receptor and has potent anti-invasive and anti-angiogenic activity in vitroand in vivo(Davies 2003). Recently, selective small molecule (indolinone) Met kinase inhibitors have been developed which reduce carcinoma cell motility and invasion (Wang 2003).

\section{Insulin-like growth factor 1 receptor}

IGF-1R and its ligands IGF1 and II are implicated in tumour cell proliferation, anchorage independent growth, migration, invasion and metastasis. Recently, it has been shown that IGF-1R induces MT1-MMP, MMP-2 and VEGF-C in a PI3 kinase dependent manner. Also, in double transgenic mice (RIP1-Tag2 x RIP7-IGF$1 \mathrm{R})$ the intermediate, encapsulated stage normally seen in the pancreatic tumours of the former mice was bypassed and highly invasive carcinomas, metastatic to lymph nodes developed. Antisense and dominant negative approaches, antibodies, peptide analogues and recently a small molecule kinase inhibitor of IGF-1R have shown therapeutic effects in vitroand in vivo. (Zhang, 2003).

\section{Fibroblast growth factor receptors (FGFR)}

Fibroblast growth factors (FGF1, FGF2 and related polypeptides) and their receptors represent one of the largest families of growth factors for cells of mesodermal and neuroectodermal origin. They are of clinical significance in melanomas, sarcomas, pancreatic and urinogenital tumours. FGFs/FGFR are often upregulated in cancers - FGF2 particularly at the invasive edge and are associated with upregulation of MMPs. FGFs also synergise with VEGF and induce proteases in endothelial cells and their differentiation into capillary-like tubes in tissue cultures. Both FGFs and VEGFs are normally sequestered within the extracellular matrix, from which they are released by tumour and/or host enzymes - another example of a cascade of events promoting several aspects of tumour progression.

FGF receptors have been considered as a therapeutic target in cancer and inhibitors such as soluble (decoy) receptors, heptapeptides and antisense constructs have shown anti-proliferative, anti-invasive and anti-angiogenic activity. FGFR have also been exploited for delivery of suicide gene therapy vectors and several companies are developing small molecule inhibitors of FGFR tyrosine kinase activity (Manetti, 2003).

\section{Platelet-derived growth factor receptors (PDGF-R)}

PDGF-R are expressed on cancers of mesodermal and neurectodermal origin and also on endothelial cells, hence inhibitors may be expected to have both antitumour and antiangiogenic effects. STI571, a low molecular weight kinase inhibitor designed as an antagonist to the Bcr-Abl kinase, also prevents activation of 
PDGF-R. This compound showed good activity against ovarian carcinoma xenograft growth and dissemination in the peritoneal cavity in association with apoptosis of tumour-associated endothelial cells and reduced microvessel density (Apte 2004). The same compound also inhibits growth and metastasis of orthotopic pancreatic carcinoma xenografts, suggesting much wider applications than its original role in CML. Novel inhibitors with greater specificity will certainly follow.

\section{Eph receptors}

Eph receptors and their ephrin ligands have emerged as an important family of RTKs which mediate cell shape, adhesion and motility. They are unusual in that both are membrane bound and signalling is bi-directional. Both are frequently over-expressed in cancers and have been implicated in invasion and angiogenesis. EphB4 and ephrin-B2 are overexpressed in colon cancer. Ephrin $A 1$ is upregulated during melanoma progression and may correlate with endothelial cell invasion. Recently, it was shown that EphB1 activates Src and the MAPK pathway to potentiate cell motility (Vindis 2003).

Although the development of inhibitors is in its infancy, EphB2 has been explored as a target for antibody drug conjugates and soluble Eph A receptors have been shown to inhibit tumour growth and angiogenesis in vivo. Interestingly, while both soluble EphA2 and EphA3 were equally effective, the former had no direct effects on tumour cells in vitro, but inhibited endothelial cell migration in response to tumour cells, suggesting indirect effects in vivo(Brantley, 2002).

\section{Transforming growth factor $\beta$ receptors (T $\beta R$ )}

The TGF $\beta$ ligands bind to a heteromeric complex of serine/ threonine kinases, the type I and II receptors (T $\beta R 1$ and T $\beta R 2$ ). TGF $\beta 1$ protein levels are increased at the invasive edge of breast carcinomas and in lymph node metastases. Mutations in the pathway have been found in human cancers which seem to shift the balance from TGF $\beta$ induced mitogenic suppression towards autocrine and paracrine induction of invasive and angiogenic phenotypes.

Because of this dual role and the fact that TGF $\beta$ is important for maintenance of normal tissue homeostasis, the development of inhibitors has been slow, since it is necessary fully to understand the nature and timing of the "switch" in cellular responses. Nevertheless, a number of blocking antibodies, antagonistic peptides and small molecule inhibitors are now in preclinical and early clinical trials (Dumont 2003). A soluble Fc:TGF $\beta$ type II receptor fusion protein inhibited tumour cell motility, intravasation and metastases. The effects correlated with inhibition of Akt activity and downstream phosphorylation of FKHRL1. In a similar study, MMTV-neu transgenic mice were protected from the development of metastases with no apparent adverse effects and modulation of angiogenesis was suggested as a contributory mechanism (Yang 2002).

TGF $\beta$ can promote angiogenesis via multiple mechanisms, including upregulation of VEGF expression and recruitment of pericytes. In addition, it has been implicated in $17 \beta$-oestradiolmediated vessel assembly, since oestrogens induce breast carcinoma cells to secrete TGF $\beta$ and VEGF. Endothelial cells incubated either directly with TGF $\beta$ or with culture supernatants from oestrogen-stimulated MCF7 cells form tubules on matrigel; these effects were blocked by anti-estrogenic compounds and also by EGFR inhibitors, indicating cross-talk between these pathways (Soares 2004). Thus, depending on the tumour in question and its molecular phenotype, TGF $\beta$ signalling pathway antagonists may be expected to inhibit invasion, angiogenesis or both and the future development of agents suitable for prolonged clinical use is awaited with interest.

\section{Hypoxia: promoter of both angiogenesis and invasion}

Areas of hypoxia are common in tumours and have been linked to induction of angiogenesis via a heterodimeric transcription factor, HIF-1. The HIF-1 $\alpha$ component normally has a short halflife, but is stabilised by hypoxia and hypoglycaemia; its overexpression is associated with poor prognosis in several cancers (Semenza 2003). HIF-1 activity results in the transcriptional upregulation of many angiogenic factors including VEGF-A, VEGFR-1 and 2, IL-8, inducible nitric oxide synthase (iNOS) PDGF and angiopoetin 2.

Hypoxia is now known also to be able to potentiate tumour cell invasion (Subarsky 2003). HIF-1 $\alpha$ expression is commonly observed at the invading margins of human cancers and tumour cells exposed to hypoxic conditions in vitro show enhanced metastatic ability. Hypoxia or HIF-1 $\alpha$ overexpression stimulates in vitro invasion of colon carcinoma cells and these effects are reversible with HIF-1 $\alpha$ siRNA. Macrophage migration inhibitory factor (MIF) a pluripotent cytokine involved in inflammation and immunity, is induced by hypoxia and can upregulate VEGF and IL8. Anti-MIF antibodies have been shown to inhibit xenograft tumour growth and angiogenesis (Nishihira 2003). Hypoxia (or direct transfection of "angiogenic" cyokines such as IL-8) can potentiate invasion by upregulating proteases such as MMP-9, illustrating a cascade of responses, which collectively induce angiogenesis and invasion.

HIF- $1 \alpha$ also directly potentiates migration and tube formation in endothelial cells via PI3K and MAPK with potency similar to FGF2. Hypoxia induces UPAR expression in human endothelial cells, trophoblasts and tumour cells and this is associated with enhanced invasive potential. Other invasion-associated genes including cathepsin D, MMP-2, TGF $\alpha$ and autocrine motility factor are also upregulated. Hypoxia can alter tumour cell adhesion to vitronectin and fibronectin, since UPAR can interact with and modify the function of $\beta 1$ and $\beta 2$ integrins. Changes in other adhesion (or adhesion-associated) molecules (e.g. ILK, CD44, NCAM) have been defined which could enhance tumour cell detachment, dissemination and protection from anoikis. Also, colon carcinoma cells alter their expression of cytokeratins from a sessile, epithelial pattern to a motile, mesenchymal pattern (Krishnamachary 2003).

Finally, it has been shown that hypoxia may also promote invasion by transcriptional activation of the c-met proto-oncogene, that both synergise to induce invasion and that inhibition of Met expression by RNAi prevents hypoxia-induced invasion (Pennacchietti 2003). Since Met activation upregulates the uPAplasmin axis, these results are consistent with previously discussed observations.

Given these pleiotropic effects on angiogenesis and invasion, its high expression in cancers (especially metastases) and its low expression in normal tissues, HIF- $1 \alpha$ represents an exciting 
target for therapy (Rapisarda 2002). In addition, "upstream" components that regulate HIF- $1 \alpha$ expression, activation or stability may also provide novel points for intervention. These include oncogenes and signalling pathways already discussed and also $\mathrm{FIH}-1$, prolyl hydroxylases, acetyl transferase ARD-1 or histone deacetylases. Recently, a hypoxia-driven, HIF-1 independent pathway of UPA-mediated cell motility was described which offers the possibility of designing novel therapies that block redox-

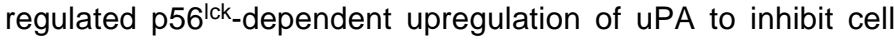
motility and metastasis (Mahabeleshwar 2003).

Finally, hypoxia-activated prodrugs or gene therapy vectors may effectively target the precise areas in tumours where angiogenesis and invasion are most active and where conventional therapies are least potent (Mazure 2003). YC-1, an agent developed for circulatory disorders is a potent HIF- $1 \alpha$ inhibitor that reduces the growth and vascularity of human tumour xenografts and could be developed for use in cancer patients if side effects such as hypotension could be managed (Yeo, 2003)

\section{Reduced dependence on microenvironmental pro-sur- vival signals}

The first step in invasion or proliferation involves detachment from the BM or ECM and cells must overcome the loss of prosurvival signals normally provided by integrin signalling pathways, primarily though the PI3 kinase-Akt-GSK3 $\beta$ pathway. It is notable that many cancer cells, early in their evolution, develop means of activating this survival pathway independently (e.g. by loss of PTEN) and of avoiding anoikis (apoptosis induced by disruption of cell-substrate connections).

The cells in which these changes have occurred may also have an added advantage: PI3 kinase activation is associated not only with pro-survival signals, but also with migration, one of the key components (together with increased proteolytic activity) of invasion and angiogenesis. Again, these events are a caricature of normal processes. During development, or wound healing, cell population expansion cannot occur without changes in adhesive interactions, (temporary) suspension of anoikis and the ability of the daughter cells to move to their new position.

\section{Changes in cell adhesion systems}

\section{Integrins}

Integrins mediate adhesion between cells and their surrounding matrices and transmit important signals regulating cell survival, differentiation and migration. Most integrin heterodimers activate ILK, FAK and/or Shc and thence downstream (eg MAPK) pathways. They may serve to prolong RTK signalling potential and induce cell motility and protease secretion in addition to mitosis. Most integrins activate PI3 kinases, leading to activation of Akt and Rho family GTPases. These interactions may provide focal points for blockade of signalling relays activated by both RTK and integrins.

Integrins also mediate tissue specific interactions leading to selective tumour cell lodgement and growth. For example $\alpha v \beta 3$ on breast and prostate carcinoma cells enables binding to vitronectin, osteopontin and bone sialoglycoprotein and potentiates cell migration. Inhibition of $\alpha v \beta 3$ inhibits bone degradation and angiogenesis in prostate carcinoma metastasis models (Nemeth 2003). $\alpha \mathrm{V} \beta 3$ is also clearly implicated in melanoma invasion. $\alpha \mathrm{v} \beta 3$ binds MMP-2 and potentiates localised proteolysis; these two molecules are found in close association at tumour invasive fronts and in newly formed blood vessels.

Similarly, $\alpha 3 \beta 1$ can promote adhesion and spreading of metastatic breast carcinoma cells on the lymph node stroma. $\alpha 3 \beta 1$ also controls expression of both MMPs and serine proteases and focuses proteolysis at the invasive front. $\alpha 6 \beta 4$ and $\alpha 6 \beta 1$ (laminin receptors) promote survival and invasion via PI3 kinase, are mobilised by EGFR activation from hemidesmosomes to F-actin in lamellipodia and have been implicated in breast cancer progression. Recently it was reported that certain integrins could directly phosphorylate receptor tyrosine kinases such as PDGF-R, Met and VEGF-R, suggesting additional effects in endothelial cells.

$\alpha v \beta 3$ and $\alpha 5 \beta 1$ are also implicated in neoangiogenesis. The former is upregulated in newly formed blood vessels and is involved in FGF2-induced angiogenesis and the latter in VEGFinduced angiogenesis. $\alpha 5 \beta 1$ appears to be a target for endostatin (Sudhaker 2003) which has also been shown to have direct inhibitory effects on colon cancer cells in vitro and in vivo in addition to its antiangiogenic effects (Dkhissi 2003). $\alpha 5 \beta 1$ inhibitors block migration of tumour cells, endothelial cells and fibroblasts on vitronectin.

Several effective integrin antagonists are already used clinically, primarily for cardiovascular and inflammatory diseases. Their development has led to important insights into the active conformations of integrins and their bi-directional signalling pathways. Structural and mutational studies have also revealed optimum binding sites for interaction of drugs and revealed their mechanisms of action (Shimaoka, 2003).

Inhibition of $\alpha v \beta 3$ may potentially interfere with both angiogenesis and invasion of certain cancer cell types, however studies in animals in which $\alpha \mathrm{v} \beta 3$ components have been "knocked out" have given conflicting results, since in some cases angiogenesis is not compromised (Stupack 2003). Antagonists of $\alpha \mathrm{V} \beta 3$ that have been tested include RGD mimetics designed to be selective versus other $\alpha \mathrm{V}$ containing integrins or $\alpha \mathrm{llb} \beta 3$. Several peptide and non-peptidic inhibitors and small molecule inhibitors of $\alpha v \beta 3$ and other integrins are now being developed for clinical use (Tucker 2003, Jin 2004). Examples are shown in Table 2.

\section{CD44}

CD44 is another adhesion molecule utilised during by lymphocyte "homing"and a change from the standard "epithelial" pattern to expression of splice variants associated with haematopoietic cells (e.g. v6) has been proposed to assist carcinoma cells in haematogenous dissemination. CD44 binds ECM components such as hyaluronic acid and the internal domain interacts with the cytoskeletal protein ankyrin and Src, thus mediating cell migration. CD44 also co-associates with and potentiates activation of erbB-2 and MMP-9 on tumour cell invadopodia (Abecassis 2003). Specific isoforms of CD44 (eg v3, 8-10) may have an additional role in metastasis since they are not only functionally coupled to Rho GTPases, but also sequester heparan sulfate binding growth factors such as FGF2 and/or VEGF which may potentiate tumour cell proliferation and angiogenesis.

The exploitation of CD44 as a therapeutic target is hampered by the complexity and variability of its expression and lack of complete understanding of its biological and prognostic signifi- 
cance. Nevertheless, antisense constructs, CD44 soluble proteins and antibodies have shown promise in animal models and CD44v6 has been proposed as a target for antibody-based therapies (Heider 2004). The recognition of osteopontin (OPN) as a key CD44 ligand has opened further opportunities for therapeutic intervention either by inhibiting OPN or its interaction with CD44. OPN acts as a survival, cell-adhesive and chemotactic factor for endothelial cells. It has consistently been associated with poor prognosis in colon and breast cancers and has been linked to bone metastasis. It is upregulated by EGF and the angiogenic cytokine FGF2 and can drive neoangiogenesis independently of its $\alpha v \beta 3$ integrin binding capacity. It further acts to induce angiogenic cytokines TNF $\alpha$ and IL-8 from monocytes, further amplifying neovascularisation. It is anticipated that better understanding of the role of the CD44/OPN/hyaluronan axis in angiogenesis and invasion may ultimately yield isoform selective inhibitors with clinical utility.

\section{Cell motility, migration and chemotaxis}

Motility, coupled with proteolysis, is the basis of tumour cell invasion, intravasation, extravasation and endothelial cell formation of capillary sprouts during angiogenesis. Many motility factors have been described (both tumour and host derived) and "growth factors" such as FGF2, TGF $\alpha$, EGF, PDGF can induce chemotactic responses in tumour cells and endothelial cells expressing cognate receptors. "Scatter factor" (HGF) is a potent host-derived motogen and tumour cells themselves secrete a variety of cytokines including AMF (a C-X-X-C cytokine induced via erbB activation) and autotaxin. Autotaxin (NPP-2) is induced by FGF2 and has also been implicated in several aspects of neoangiogenesis such as endothelial differentiation and smooth muscle cell migration. Angiogenic factors such as VEGF are also potent chemoattractants for endothelial cellsand for tumour cells, which may ectopically express VEGF receptors.

Cell migration is a highly organised and integrated process which requires the continuous assembly and disassembly of focal adhesions (to give "grip") coupled with a motor force - usually in response to a chemotactic gradient (to give directional motility). Cell movement in 2-D (haptotaxis) may be represented by the classical "3-step" process involving 1) polarised cell extension and lamellipodia formation; 2) substrate binding 3) actin-mediated cell body contraction and detachment at the rear - which is mediated by proteolytic enzymes. A form of amoeboid movement which is protease-independent has also been described in 3-D systems (Friedl 2000).

All the components involved (including actin and its partners, signalling molecules, integrins, structural proteins, adaptor molecules, microtubules etc) must be co-ordinately regulated in both time and space. Understanding the complex interplay of key molecules involved in motility and invasion is now a major research effort in both developmental biology and cancer (Mareel, 2003). Src and members of the Rho family of small GTPases (RhoA, RhoC, Rac1 and Cdc42) are important regulators of cytoskeletal organisation, cellular deformability and migration, linking both E-cadherin and integrin signalling pathways (Raftopoulou 2004). PI3 kinase is also involved in motility of both tumour cells and endothelial cells via interactions with Rac and PLC $\gamma$ has been implicated in growth factor-induced lamellipodium formation. The roles of some of the most important mediators will be discussed in more detail below, with an emphasis on their potential as targets for therapy.

TABLE 2

\section{EXAMPLES OF INTEGRINS INVOLVED IN INVASION AND ANGIOGENESIS AND THEIR POTENTIAL FOR THERAPEUTIC INHIBITION}

\begin{tabular}{|c|c|c|}
\hline Integrin & Role & Inhibitors \\
\hline $\begin{array}{l}\alpha 5 \beta 1 \\
(1)\end{array}$ & Preferentially expressed on neovasculature & $\begin{array}{l}\text { Peptide ATN-161 inhibitor of } \alpha 5 \beta 1(+\alpha v \beta 3) \text { decreases colon cancer xenograft liver metastasis and vessel density } \\
\text { Endostatin has antiangiogeneic effects, possibly via } \alpha 5 \beta 1, \alpha v \beta 3 \text { and } \alpha 2 \beta 1 \text { and direct effects on some colon cancer cells } \\
\text { Monoclonal antibodies in clinical trial }\end{array}$ \\
\hline $\begin{array}{l}\alpha v \beta 3 \\
\text { (1) }\end{array}$ & $\begin{array}{l}\text { Exclusively expressed on activated endot- } \\
\text { helial cells } \\
\text { Expression on osteoclasts may favour bone } \\
\text { resorption and tumour colonisation } \\
\text { Present on invasive melanoma cells }\end{array}$ & $\begin{array}{l}\text { Tumstatin } \\
\text { S247 peptidomimetic antagonist decreases colon cancer xenograft liver metastasis and vessel density } \\
\text { m7E3 antibody decreases prostate cancer bone metastasis and angiogenesis } \\
\text { Vitaxin/LM609 antibody in clinical trial } \\
\text { Cyclic peptide inhibitor of } \alpha v \beta 3(+\alpha v \beta 5) \text { (Cilengitide) in clinical trial }\end{array}$ \\
\hline $\begin{array}{l}\alpha v \beta 5 \\
(1)\end{array}$ & $\begin{array}{l}\text { Endothelial integrin Promotes VEGF (but } \\
\text { not FGF2) induced angiogenesis }\end{array}$ & $\begin{array}{l}\text { (Cilengitide) } \\
\text { BAl1 inhibits endothelial cell viability via } \alpha v \beta 5\end{array}$ \\
\hline $\begin{array}{l}\alpha 6 \beta 4 \\
(2)\end{array}$ & $\begin{array}{l}\text { Binds laminin } 5 \text {; important in SCC and } \\
\text { breast cancer invasion }\end{array}$ & $\begin{array}{l}\text { Si RNA > MDA MB } 231 \text { invasion } \\
\text { Loss of Id1 inhibits angiogenesis partly by downregulation of } \alpha 6 \beta 4\end{array}$ \\
\hline $\begin{array}{l}\alpha 4 \beta 1 \\
(3)\end{array}$ & $\begin{array}{l}\text { Expressed on activated endothelial cells } \\
\text { and migrating cells }\end{array}$ & Soluble antagonists inhibit angiogenesis - thrombospondin 1 dependent \\
\hline $\begin{array}{l}\alpha 1 \beta 1 \\
\alpha 2 \beta 1 \\
(4)\end{array}$ & Upregulated in response to VEGF & E7820 inhibits FGF2 induced tumour angiogenesis, growth and vessel density \\
\hline
\end{tabular}

Tumstatin $=\alpha 3$ chain of type IV collagen (cleaved by MMP-9) - inhibits endothelial cell proliferation via FAK/PI3k and $\alpha v \beta 3$ Endostatin $=\alpha 1$ chain of type XVIII collagen - inhibits endothelial cell migration on fibronectin via FAK/MAPK, $\alpha 5 \beta 1$ and $\alpha v \beta 3$ BAl1 -brain specific angiogenesis inhibitor

(1) Bind to fibronectin, vitronectin and other ECM proteins absent from basal membrane of mature vessels but present at sites of neoangiogenesis (provisional matrix), OPN

(2) Bind primarily to laminin

(3) Bind primarily to fibronectin and VCAM

(4) Bind primarily to collagen and laminin 


\section{Enzyme functions in invasion and metastasis}

Invasive tumour cells show increased proteolytic activity due to upregulation of specific genes, enhanced activation of pro-enzymes or reduced expression of inhibitors. Tumour cells may also induce expression of enzymes by neighbouring host cells and "hijack" these to potentiate invasion. Activated endothelial cells forming capillary sprouts use similar processes. The major families of enzymes responsible are the matrix metalloproteinases (MMPs), adamalysin-related membrane proteinases (ADAMs), serine-, cysteine-and aspartate proteases and heparanase.

\section{Matrix metalloproteinases}

One of the most important groups of enzymes associated with invasion and angiogenesis are the matrix metalloproteinases. Different cancers may show different patterns of expression and it is the overall balance between tumour- and host-derived MMPs and their natural inhibitors (TIMPs) that determines the net proteolytic balance within a tumour - particularly at the invasive edge. Their pleiotropic effects have been well described in many recent reviews and in this piece the focus will be on illustrating where invasion and angiogenesis are mutually dependent on MMP activity.

Colorectal carcinoma cells over-expressing EGFR have a predilection for growth in the liver where there are high concentrations of its ligands. These require proteolytic cleavage for activa- tion and this may be potentiated by the upregulation of specific MMPs via activated EGFR (O-charoenrat 2002b). Cleaved fragments of several ECM proteins are also potently motogenic, stimulating directional migration of tumour cells and also endothelial cells. Angiopoietin 2 induces glioma invasion through activation of MMP-2; these and the following examples show how "angiogenic factors" can induce invasion effectors and vice versa.

During angiogenesis, "invasion" of capillary sprouts requires local proteolysis (mediated in part by upregulated MT1-MMP, MMP-2 and MMP-9 together with UPA) and in addition MMP-9 has been implicated in the "angiogenic switch" by releasing VEGF from sequestration in the ECM. MT1-MMP upregulates expression of VEGF-A, even in MMP-2 negative cells, hence this is independent of MMP-2 activation but requires Src tyrosine kinases. Conversely, VEGF-A upregulates MMP2 and FGF2 upregulates multiple MMPs, indicating that microenvironmental context can differentially regulate protease expression.

Early MMP inhibitors lacked selectivity, had serious side effects and suffered from being inappropriately evaluated in late stage disease. However, recently many different classes of inhibitors have been shown to inhibit both tumour invasion and angiogenesis (Table 3 ) and future developments are promising. (Bauvois, 2004). For example, MTI-MMP siRNA inhibits tumour cell migration and invasion, even though other MMPs continued to be expressed, suggesting that the membrane MMPs may have pivotal functions in tumour progression (Seiki 2003).

TABLE 3

MMP INHIBITORS: EVIDENCE FOR ANTI-INVASIVE AND ANTI-ANGIOGENIC ACTIONS

\begin{tabular}{|c|c|}
\hline Inhibitor & Effects \\
\hline Batimastat broad spectrum & Inhibited osteolytic bone metastases in breast carcinoma xenograft, evidence of antiangiogenic effects \\
\hline Marimastat broad spectrum & $\begin{array}{l}\text { Inhibited gastric carcinoma xenograft dissemination, MMP activity and angiogenesis } \\
\text { Inhibited rat mammary carcinoma lung and lymphatic metastasis and angiogenesis } \\
\text { Inhibits in vitro angiogenesis }\end{array}$ \\
\hline Prinomastat inhibits MMP-2,-3,-9,-13 and -14 & Reduces systemic metastases of lung cancer xenografts in combination with carboplatin. Phase 1 trial completed \\
\hline MM1270 (CGS27023A) broad spectrum & $\begin{array}{l}\text { Decreased MMP-2 and }-9 \text {, in vitro invasion and lymphatic metastasis of Lewis lung carcinoma, LEC invasion and tube formation } \\
\text { in vitro }\end{array}$ \\
\hline ONO-4817 & $\begin{array}{l}\text { Controlled xenograft lung metastases and reduced their expression of MMP-2 and }-9 \text { in combination with docetaxel } \\
\text { Inhibited Renca lung metastasis and angiogenic response }\end{array}$ \\
\hline FYK-1388 Broad spectrum & Inhibited HT1080 growth, lung metastasis, MMP-2 and -9 expression and angiogenesis in vivo \\
\hline MMI- 166 orally active MMP- 2 and -9 inhibitor & Inhibited lung metastasis of SCCHN, colon, pancreatic tumour xenografts, MMP-2 and -9 activity and microvessel density \\
\hline BMS-275291 inhibits MMPs but not other MPs & Inhibited B16 lung metastases and angiogenesis in vivo \\
\hline TN-6b broad spectrum inhibitor & Inhibited invasion of Lewis lung carcinoma in vitro, decreased MMP-2 and -9 activity, inhibited angiogenesis and metastasis in vivo \\
\hline KB-R7785 Inhibits MMP-1, -3, -9 & Inhibited growth of C-26 mouse colon tumour growth, lung colonisation and angiogenesis \\
\hline PMO antisense inhibitor of MMP-9 & Attenuates DU145 prostate carcinoma invasion in vitro, growth and angiogenesis in vivo \\
\hline Adeno-associated virus delivery of TIMP-1 & Inhibited growth of Kaposi sarcoma, MMP expression and angiogenesis in vivo \\
\hline AdTIMP-2 Adenovirally delivered TIMP-2 & Local delivery reduced syngeneic tumour growth, angiogenesis and metastasis \\
\hline Lentiviral delivery of PEX non-catalytic fragment of MMP-2 & Inhibited EC invasion and tube formation, in vivo xenograft growth and angiogenesis \\
\hline SiRNA MT1-MMP & Suppresses tumour migration and invasion in vitro; decreases MMP-2 activity and CD44 shedding \\
\hline "K" compounds (allylthiopyridazine derivatives) inhibit MMP-2 (not & Inhibit tumour cell migration and invasion and angiogenesis \\
\hline
\end{tabular}




\section{ADAMs}

The ADAMs are transmembrane proteins containing MMP and disintegrin domains. They regulate growth factor signalling and adhesion, mainly because their extracellular domain anchors bioactive molecules including cytokines, enzymes, adhesion molecules, growth factors and their receptors; this region can be cleaved by sheddases (some of which are themselves ADAMs). ADAM regulated molecules include TNF $\alpha$ (released by TACE/ ADAM17)and the Notch 1 ligand delta, which is released by ADAM 19 and is important in cell fate determination and angiogenesis.

Transmembrane proteases as a group (including ADAMs, MTMMPs, ectopeptidases aminopeptidase N/CD13 and dipeptidyl peptidase IV/CD26) are implicated in cell proliferation, motility, shedding of cell adhesion molecules and angiogenesis (release of angiogenic cytokines and endothelial cell responses). APN/CD13 is differentially expressed on activated endothelial cellsand inhibitors such as bestatin, amastatin and blocking antibodies are antiangiogenic. Targeted inhibition and knock out studies are revealing the full complexity of transmembrane protease functions. Inhibitors of DPPIV and TACE are in development or clinical use for diabetes and arthritis and it is likely that cancer therapy will also be investigated (Bauvois, 2004)

\section{Serine proteases}

Urokinase and tissue-type plasminogen activators (UPA and tPA) cleave plasminogen into its active form plasmin. UPA is secreted in a latent pro-form which binds to a GPI-linked receptor UPAR, where it initiates a proteinase cascade that assists breakdown of the ECM and potentiates tumour and endothelial cell migration, partially by activation of MMPs including 1,7 and 9. uPA and plasmin also proteolytically cleave and activate latent growth factors including HGF, FGF2 and TGF $\beta$, all of which may contribute to invasion and angiogenesis. uPA can be regulated by osteopontin (OPN), a glycosylated glycoprotein that binds to several integrins (including $\alpha v \beta 3$ ) and CD44 variants. Enhanced $u P A$ secretion is thought to be mediated via NFKB and PI3 kinase-Akt-IKK pathways.

The role of uPA in chemotaxis is well established. It is independent of its proteolytic function, but utilises the kringle domain. Recently it has been shown that UPAR requires endo180, a constitutively recycling endocytic receptor, for activation of Rac and directional sensing during chemotaxis, whereas the chemotactic response to uPA does not (Sturge, 2003). Since Endo180 is expressed on tumour cells and endothelial cells, it could represent a general mechanism of directional migration during angiogenesis and invasion.

Plasminogen activator inhibitor type 1 (PAI-1) is the main natural antagonist of UPA and tPA. It not only regulates their proteolytic activity, but also their level of receptor binding by promoting endocytosis of the trimolecular complex of UPA/UPAR/PAI-1. Again, (similar to observations with TIMPs) there is an apparently paradoxical association between high levels of PAI- 1 and poor prognosis in several cancers. The reasons for these observations are not entirely clear. However, recent elegant experiments testing angiogenesis in tissues from mice deficient in one or more components of the PA system clearly showed that PAI- 1 was critical for controlling plasminmediated proteolysis and microvessel formation. In addition, PAI-1 promotes angiogenesis at physiological concentrations, but is antiangiogenic at higher concentrations.
These observations again show us that control of angiogenesis and metastasis is a balance of integrated molecular messages. Labelling entities "inhibitors" or "activators" may underestimate the complexity of designing therapeutic intervention strategies. Nevertheless, treatment of cells with anti-uPA antibodies or small molecule inhibitors has been shown to prevent invasion and angiogenesis in experimental models and both UPA and UPAR are considered to be attractive potential targets for therapy in cancer (Sidenius 2003, de Bock 2004).

Maspin, a serine protease inhibitor, prevents prostate cancer cell motility, invasion and collagen degradation in vitro and xenograft growth, angiogenesis and bone degradation in vivo (Schaeffer 2003). However, other enzymes can act in concert with serine proteases and in particular cancer cell intravasation during metastasis requires both MMP-9 and UPA/UPAR. Attempts are now being made to inhibit two or three protease systems simultaneously. An adenoviral vector expressing both antisense uPAR and MMP-9 was particularly efficient at inhibiting glioblastoma cell invasion (in vitro and in vivo) tumorigenicity and angiogenesis (Lakka 2003). In early stage development are even more ambitious recombinant trifunctional inhibitors targeting cysteine proteases, UPA and MMPs, which have been shown to inhibit ovarian carcinoma cell invasion in vitro (Krol 2003). Future developments are awaited with interest.

\section{Cysteine (and aspartyl) proteases}

Cathepsins B, H, D and L have been shown to participate in tumour growth, vascularisation, invasion and metastasis. Cathep$\sin B$ has been shown to affect cell motility, ECM breakdown, activation of other proteases (including UPA and MMPs) and degradation of TIMPs 1 and 2 . It (together with cathepsin L) has been implicated in prostate carcinoma invasion and their natural inhibitors (cystatins) have been considered for therapeutic use. Since cathepsin B has been detected in capillaries near the invading edge of gliomas and prostate carcinomas and in activated endothelial cells in vitro, it may also contribute to angiogenesis. ANO-2 is an ozonide inhibitor of both cathepsin B and UPA, which effectively inhibits angiogenesis and experimental tumour metastasis. Development of specific therapeutic pharmacological inhibitors is in its infancy, due to some uncertainties of the viability of the cathepsins as targets and the fact that their role is probably minor relative to MMPs and serine proteases.

\section{Heparanases}

Apart from structural proteins, the other major components of the BM and ECM are glycosaminoglycans, predominantly heparan sulfate proteoglycan (HSPG). Heparanase degrades the HS side chains of HSPGs and, like the proteases described above also regulates release of cytokines such as FGF2 and other heparinbinding growth factors. Similarly, UPA and tPA can be released from $\mathrm{HS}$ by heparanase, further potentiating proteolytic and mitogenic cascades. Heparanase is frequently upregulated in malignancies, is associated with increased microvessel density, can be regulated by oestrogen in breast cancerand has been implicated in both invasion and angiogenesis. It also modulates cell adhesion independently of its proteolytic function. Heparins and structurally similar polysaccharides, suramin analogues, laminarin sulfate and antisense constructs have been shown to inhibit invasion and angiogenesis via multiple mechanisms and the development of 
novel inhibitors suitable for clinical use is a viable prospect (Vlodavsky 2002).

\section{Signalling pathways}

\section{Focal adhesion kinase (FAK)}

FAK was first identified as a substrate and binding partner for the Src oncogene and is a key player in cell-matrix adhesion and a regulator of many processes involved in neoplastic progression. FAK directly associates with the cytoplasmic tail of integrins, ezrin and paxillin and indirectly with EGFR and PDGFR. The major site of autophosphorylation of FAK (Y397) is a binding site for the SH2 domains of $\mathrm{Src}, \mathrm{PI} 3$ kinase and PLC $\gamma$. Phosphorylation of FAK is necessary for integrin signalling and to potentiate motility (GabarraNiecko 2003).

FAK is expressed on both tumour cells and endothelial cells. It links integrins to the MAPK pathway and is important in promoting survival of cells and protecting them from anoikis. This could be critical in areas where the normal survival signals derived from cell-cell and cell-matrix interactions are compromised - e.g. for both disseminating cancer cells and for endothelial cells as they venture into damaged tissues (or cancers) to effect neoangiogenesis. Dominant interfering FAK (FRNK) inhibits MMP2 and/or MMP-9 production and invasion of prostate and lung adenocarcinoma cells and brain microvascular endothelial cells. Elevated levels of FAK were found in the vasculature of grade III and IV astrocytic tumours, suggesting a role in brain tumour angiogenesis and progression (Haskell 2003). It is being actively investigated as a potential cancer therapeutic target, although more information on its role in maintaining normal tissue homeostasis is required.

\section{Integrin linked kinase (ILK)}

Integrin-linked (serine-threonine) kinase co-ordinates receptor tyrosine kinase and integrin signalling. ILK interacts with the cytoplasmic domains of integrins $\beta 1$ and $\beta 3$ and has been implicated not only in Akt activation, but also in phosphorylation of GSK3 $\beta$. This provides links with the $\beta$-catenin/APC pathway and hence further possible roles in cell deformability and motility. It

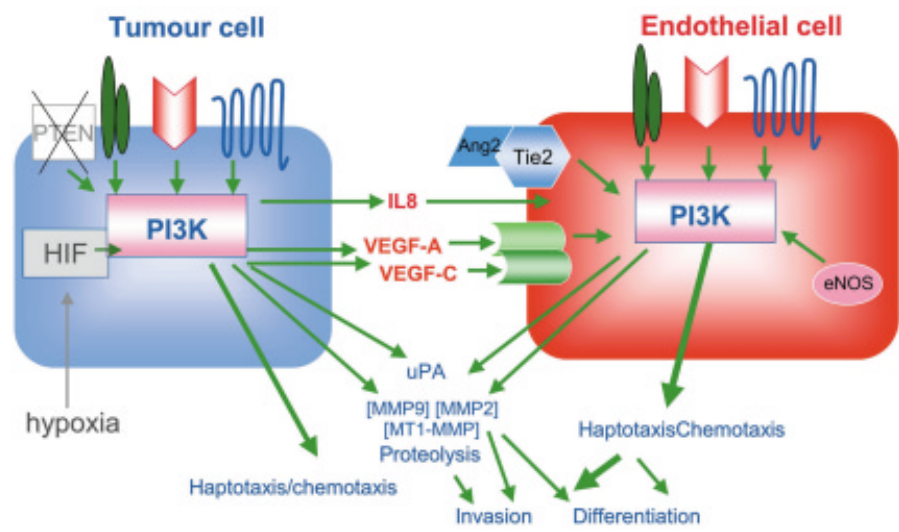

Fig. 3. Roles of PI3K in invasion and angiogenesis. $P / 3$ kinase roles are shown in cartoon form as described in the text. This enzyme is a pivotal point in signalling cascades, being activated by multiple RTK, integrins and GPCR. It fulfils many different functions in both tumour and activated endothelial cells. has also been implicated in hypoxia-independent upregulation of HIF- $1 \alpha$ and VEGF induced by RTK, loss of PTEN or by activating mutations in $\mathrm{PI} 3$ kinase or Akt. In prostate carcinoma cells, inhibition of ILK downregulated HIF-1 $\alpha$ and VEGF expressionand in endothelial cells its inhibition prevented VEGF-mediated cell migration and capillary formation (Tan 2004). ILK may therefore represent another molecular target whose inhibition can affect both tumour cell induction of, and endothelial cell responses in, neoangiogenesis.

\section{Phosphatidylinositol 3 Kinase (PI3K)}

PI3K activity is tightly regulated in normal tissues, but it is constitutively active in up to $50 \%$ of human cancers. Hyperactivation of the PI3K signalling cascade can be induced by overexpression or upregulation of $\mathrm{PI} 3 \mathrm{~K}$ or Akt isoforms and inactivation/silencing of PTEN. Tumour cells with activated PI3K signalling are able to avoid anoikis, a specialised form of programmed cell death that normal epithelial cells undergo when they are deprived of survival signals from physiological substrates. When malignant cells are grown in 3 dimensional culture, they are reverted to a normal phenotype by exposure to PI3K antagonists. This is due to two complementary downstream effectors: Akt, a control point for cell proliferation and Rac which is involved in cell polarity and motility.

PI3K mediates EGF and HRG $\beta$ stimulated breast carcinoma adhesion and migration driven by $\beta 1$ integrin. Also, $\alpha_{6} \beta_{4}$ integrin activates PI3K to promote lamellae formation and invasion. Overexpression of PTEN can inhibit tumour cell migration by regulating, via $\mathrm{PI} 3 \mathrm{~K}$, dynamic cell surface interactions that involve integrins, FAK and the cytoskeleton. Lamellipodia extension requires the PI3 kinase $p 110 \alpha$ isoform to recruit Rac or cdc42, thus activating PAK1 kinase, LIM kinase, which targets cofilin, a molecule involved in actin depolymerisation in response to EGF and other motogenic ligands.

PI3K regulates the secretion of MMP-9 and UPA, which are required for tumour cell invasion, endothelial cell and vascular smooth muscle cell migration. The PI3K-Akt-mTOR pathway plays a central role in IGF-1R mediated tumour cell invasion via co-ordinated upregulation of MMP-2 expression and its activator MT1-MMP (Zhang, 2003). Thus the accumulated evidence clearly demonstrates that many types of tumour cells and also endothelial cells utilise PI3K signalling for motility, chemotaxis and invasion of the ECM.

$\mathrm{PI} 3$ kinase promotes angiogenesis at several levels (reviewed in Brader 2004). VEGF and IL-8 transcription is induced by activation of the PI3 kinase pathway via HIF1 $\alpha$ or activated oncogenes (Mazure, 2003, O-charoenrat 2000). Loss of PTEN upregulates this pathway and reintroduction of PTEN or the PI3 kinase inhibitor LY294002 reduces constitutive and hypoxiainducible levels of VEGF and angiogenic potential.

$\mathrm{PI} 3$ kinase is also downstream of the major VEGF receptors in endothelial cells. VEGF activation of PI3k is mediated via FAK and both are implicated in VEGF-mediated endothelial cell migration. PI3 kinase is involved in endothelial cell survival and migration mediated by angiopoietin and eNOS. Recently it has been shown that topotecan inhibits both VEGF- and FGF2-induced endothelial cell migration via downregulation of the PI3k/Akt pathway.

Thus PI3 kinase signal transduction is implicated in multiple key angiogenic pathways at both afferent and efferent levels and 
in tumour motility and invasion (Fig. 3). In spite of the fact that current inhibitors lack specificity and have not yet been developed for clinical use, evidence suggests that this pathway may yield valid therapeutic targets. PI3 kinase inhibitors LY294002 and wortmannin inhibit growth of several tumour xenografts. The mTOR inhibitor rapamycin also prevents both a) induction of VEGF and b) endothelial cell proliferation and tube formation, resulting in significant inhibition of angiogenesis, tumour growth and metastasis in vivo (Guba 2002). There are many initiatives currently underway aiming to develop more potent, selective, or isoform-selective inhibitors of PI3K, Akt and downstream effectors, which it is hoped will provide a useful adjunct to conventional therapies via prevention of angiogenesis, invasion, drug resistance and radioresistance.

\section{Phospholipase $C \gamma$}

PLC $\gamma$ is activated by many RTKs including Met, EGFR, PDGF$R$, IGF-1R, FGFR-1, VEGFR-2 etc. Like PI3K, it is upregulated in many cancers and is a key enzyme in lipid signalling, generating second messengers IP3, Ca++ and diacylglycerol. PLC $\gamma$ can also be activated by ICAM-1 and certain integrins, but all are linked with actin cytoskeleton remodelling, cell spreading and motility. It has been implicated in tumour cell invasion and angiogenesis. (Fig. 4). Currently there are no selective inhibitors in clinical use, although PLC $\gamma$ inhibition in experimental models using a pharmacological agent, (U73122) and dominant negative or antisense constructs has shown potential for anti-invasive activity (Wells 2003, Eccles 2003).

\section{Src family tyrosine kinases}

The Src family tyrosine kinases are activated by RTKs (especially Met and EGFR), G-proteins (including chemokine receptors) and integrins. They regulate multiple cellular functions such as proliferation, adhesion and migration via interactions with $F A K$, paxillin, WASP/Scar/Rho (actin cytoskeleton) $\beta$-catenin (cell-cell interactions) and both MAPK and PI3K signalling pathways. Overexpression/hyperactivation of Src has been identified in many cancers, notably breast and colon (metastases in particular) and often correlates with poor prognosis (Summy 2003).

Several experimental studies indicate that transfection or hyperactivation of $c$-Src increases tumour cell proliferation, upregulation of $\mathrm{UPA}(\mathrm{R})$, calpain and MMP proteolytic systems, invasion and/or metastasis. Conversely, inactivation by the negative regulator $\mathrm{Csk}$, dominant negative constructs, peptidomimetics or pharmacological inhibitors can reverse these effects. For example, pyrrolopyrimidines CGP77675 and CGP76030 inhibited proliferation, adhesion, matrigel invasion and MMP-9 production in prostate carcinoma cells (Recchia 2003) and pancreatic carcinomas. A similar compound, PP2, (or Src antisense constructs) repressed UPAR transcription and inhibited invasion in colon carcinoma cell lines (Boyd, 2004). None of these has yet been developed for clinical use, but a new class of orally active anilinoquinazoline compounds (Ple 2004)and bone-targeted agents such as AP-22408 and AP-23236 (Shakespear 2003) could lead to novel inhibitors of tumour invasion.

Src plays an important role at many levels in angiogenesis. PP2 or Src antisense oligonucleotides inhibit endothelial cell migration and tube formation in vitro and microvessel density in vivo (Kumar 2003). Dominant negative Src mutants and PP2 inhibit VEGF and FGF-2 induced angiogenesis in vivo via reduction in phosphorylation of Src substrates cortactin and paxillin affecting cell motility in both endothelial cells and vascular smooth muscle cells (Kilarski 2003). Existing vascular structures are unaffected, which would be important for therapeutic use and in vivotreatment of mice for several weeks with some Src inhibitors has been well tolerated.

Interestingly, resversatrol, a polyphenolic compound found in red grapes with known antiangiogenic activity, inhibits VEGFmediated migration and tube formation via interference with Src-

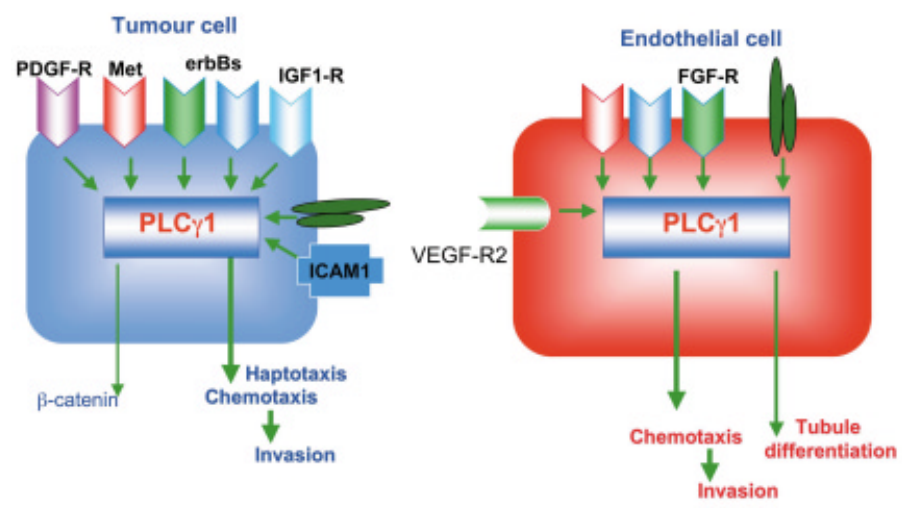

Fig. 4. Roles of PLC $\boldsymbol{\gamma}$ in invasion and angiogenesis. PLC $\gamma$ is activated by many RTK and some adhesion molecules, as described in the text. Its prime role in both tumour cells and endothelial cells seems to be in cell motility, chemotaxis, and invasion.

dependent phosphorylation of VE-cadherin and $\beta$ catenin. (Lin 2003). Src and FAK are also implicated in IL-8 signalling which, in addition to its role in angiogenesis, has been shown to confer androgen-independent growth and migratory ability in prostate carcinoma cells. (Lee 2004).

\section{Map kinases, Rho/ROCK}

Three distinct MAP kinase families are activated downstream of receptor tyrosine kinases including EGFR and VEGFR (RasRaf-Mek-Erk), by stress (MEKK-JNK) and cytokines (MLKs-p38). They may have differential roles in cell proliferation, motility and angiogenesis, although the Ras-MAPK pathway is implicated in all of these processes (Reddy, 2003). Certain MAPK are also implicated in protection of cells from apoptosis in ectopic and hypoxic environments. The major pathways involve upregulation of proteases, angiogenic cytokines and activation of Rho and downstream effectors. RhoA GTPase is implicated in tumour progression and invasion of human microvascular cells and induces MMP-9 expression at CD44 lamellipodial focal complexes (Abecassis 2003). RhoC is involved in tumour cell migration, invasion and metastasis.

MAPK inhibitors are widely used as experimental tools, some (e.g. Cl-1040) have been shown to inhibit experimental metastasis (Collisson 2003) and others (e.g. BAY-43-9006 Raf/VEGFR2 kinase inhibitor) are now in clinical trial. Ras/Rho farnesyltransferase and geranylgeranyl transferase inhibitors have had a chequered history, but better understanding of their roles may yet yield useful drugs. A novel inhibitor of the Rho effector ROCK (Wf-536) has potent anti-invasive and anti- angiogenic effects in vitro and in vivo (Nakajima 2003) which are synergistic 
with MMP inhibitors. It is likely that many of these signalling molecules will prove valuable targets for cancer therapy providing that inhibitors with adequate selectivity and potency can be developed.

\section{Other potential targets for anti-invasive and anti-angio- genic therapy}

\section{Molecular chaperone HSP9O}

Molecular chaperones such as heat shock protein 90 (HSP90) assist the folding, maturation and subcellular localization of their client proteins and target damaged proteins for degradation via the proteasome. Hsp90 has recently emerged as a novel target for therapy in cancer (Maloney 2002, Goetz 2003).

Many oncoproteins (such as erbB-2, EGFRvIlI, Met, mutant Src) depend upon Hsp90 for their maturation and/or maintenance (Table 4) and their ligands upregulate Hsp90. Chaperone inhibitors may be expected to have pleiotropic effects since these receptors are implicated in cell motility and invasion in addition to mitosis. Geldanamycin Hsp90 inhibitors potently suppress tumour cell invasion, possibly via downregulation of Met and prevention of uPA-mediated plasmin activation, although there may be additional molecular targets on this pathway. These effects were obtained at femtomolar concentrations, significantly below their growth inhibitory concentrations (Webb 2000). 17AAG, an analogue of geldanamycin, also modulates the metastatic phenotype: E cadherin is upregulated, levels of MMP- 9 and VEGF expression reduced and tumour cell invasion through matrigel is inhibited.

Several signaling molecules involved in angiogenesis may also be deregulated by Hsp90 inhibition which may provide an additional benefit of this approach. Interestingly, one of the first natural HSP90 inhibitors discovered (Herbimycin A) was noted to have strong antiangiogenic potential, then thought to be due to its inhibition of Src family kinases. We have shown that geldanamycin and 17-AAG modulate expression of Hsp90 client proteins in human endothelial cells (such as Akt, Raf-1, Cdk-4) as previously described for tumour cells. Also, many other key functions required for angiogenesis were potently inhibited, e.g. migration in response to VEGF, uPA production, invasion through matrigel and

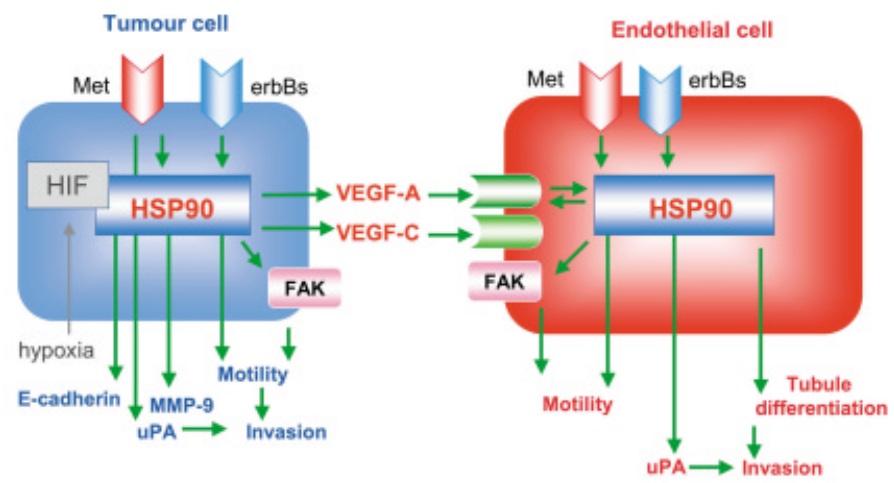

Fig. 5. Roles of HSP90 chaperone in invasion and angiogenesis. HSP9O is an important mediator of several signalling pathways as it "chaperones" many TKR, second messengers, enzymes and transcription factors in both tumour cells and endothelial cells. It is a key enabler of functions involved in cell survival, invasion and angiogenesis, making it an attractive target for therapy.

\section{TABLE 4}

\section{SOME KEY CLIENT PROTEINS OF HSP90}

\begin{tabular}{ll} 
Class of molecule & Examples \\
\hline Receptor tyrosine kinases & erbB-2, EGFR, EGFRVIII, met, kit? \\
Non-receptor kinases & Src, PDK1, Akt, Raf, G-protein receptor kinases \\
Steroid receptors & Androgen receptor, oestrogen receptor \\
Enzymes & eNOS, hTERT (catalytic subunit) \\
Transcriptional regulators & HIF-1 $\alpha$, mutant P53 \\
Cell cycle/apoptosis related proteins & CDK4, polo kinase, survivin \\
\hline
\end{tabular}

Those in bold type are directly implicated in angiogenesis

tubule differentiation (Eccles, 2004).

Geldanamycin inhibits angiopoietin-1 stimulated eNOS, nitric oxide production, migration and differentiation in pig aortic endothelial cells (Chen 2003). In both studies, Akt may be implicated, since it is plays a role in cell survival and motilityand similar results were seen with the PI3 kinase inhibitor LY294002. However, other signaling molecules such as FAK may be involved either directly (as client proteins) or indirectly (as downstream mediators).

In vivo, indirect inhibition of angiogenesis (at the afferent/ induction level) may be obtained via downregulation of hypoxia- or oncogene-induced VEGF, since both HIF- $1 \alpha$ and major oncogenic RTKs are client proteins of HSP90. Geldanamycin induces degradation of HIF- $1 \alpha$ in prostate cancer cells and a radicicol derivative (KF58333) inhibited expression of HIF-1 $\alpha$ and VEGF and reduces vascularisation and growth of breast carcinoma xenografts (Kurebayashi 2001)

Tumours grown in mice with deficient angiogenesis (id-/- mice) are more sensitive to 17AAG compared with those in wild type mice (Candia 2003). Therefore 'classical' angiogenesis inhibitors in combination with inhibitors of $\mathrm{Hsp} 90$ function may be useful in anticancer therapy. Also, Hsp90 inhibitors may target pivotal points in both tumour and endothelial cell survival, proliferation and invasion (Fig. 5) providing a combinatorial approach to attack multiple features of the malignant phenotype.

\section{Histone deacetylases (HDACs)}

Histone deacetylases are a family of enzymes that, together with histone acetyltransferases, control the acetylation of histones and the accessibility of DNA to the transcriptional machinery. HDAC inhibitors such as SAHA and trichostatin-A (TSA) have been shown to induce differentiation or apoptosis in a variety of cancer cellsand to inhibit the growth of human tumour xenografts.

Of interest to this review is the fact that HDAC inhibitors can subvert many functions associated with angiogenesis including VEGF-induced upregulation of VEGF-R, endothelial cell migration and capillary formation. No effects were seen in resting endothelial cells, suggesting that the HDAC inhibitors may have a degree of selectivity for neoangiogenesis (Deroanne, 2002). HDAC1 expression is increased by hypoxia and TSA upregulates p53 and VHL under hypoxic conditions, thereby inhibiting expression of HIF1 and VEGF. Another HDAC inhibitor, FK228, can subvert angiogenesis by preventing induction and transcriptional activity of HIF $1 \alpha$ and also inhibits VEGF and FGF2 induction independently of HIF1 $\alpha$ (Sasakawa 2003).

A candidate metastasis suppressor gene, MTA1, has been found to interact with HDAC-1, suggesting that its mode of action may be via transcriptional repression involving acetylation. The HDAC inhibi- 
tor apicidin has been found to prevent $\mathrm{H}$-ras-induced invasive phenotypes (and angiogenesis) via downregulation of MMP-2 (Kim 2004). Similar results were obtained using TSA, which inhibited MMP-2 activation and invasion of human lung carcinoma cells via upregulation of RECK, a metastasis and angiogenesis suppressor gene. Thus although in the relatively early stages of development as anticancer agents, HDAC inhibitors could prove to be important regulators of both invasion and angiogenesis.

\section{COX-2}

Cyclo-oxygenase 2 (COX-2) is a key enzyme in the synthesis of prostaglandins and thromboxanes and is highly expressed in tumour cells, stromal cells and activated endothelia (Ruegg 2004). In several cancer types (especially colorectal, breast and lung), COX-2 expression is correlated with poor prognosis and/or degree of vascularity. Transgenic overexpression of COX-2 promotes tumour formation, in association with enhanced angiogenesis. Colon adenoma/carcinoma development in APC-/- mice crossed with COX-2-/- mice is significantly inhibited compared with the single (APC) knockouts, apparently due to lack of stromal COX-2 available to induce VEGF. In addition, in human endothelial cells, COX-2 expression is regulated by hypoxia, suggesting a positive feedback loop within developing tumours (Gately, 2003).

Several compounds with antiangiogenic activity interfere with COX-2 expression - for example thalidomide and cyclosporin A. Protective effects of COX-2 inhibitors (such as non-steroidal antiinflammatory drugs, NSAIDS) may be due in part to inhibition of angiogenesis, since such agents can block both production of angiogenic factors and endothelial cell responses to VEGF (Iniguez 2003) and HGF (Sengupta 2003).

VEGF and FGF2 levels increase in response to $P G E_{2}$ and several prostanoids can induce angiogenesis in vivo. In turn, VEGF and HGF activate phospholipase $A_{2}$ mediated release of arachidonic acid and induce COX-2 expression, thereby increasing $\mathrm{PGI}_{2}$ and $P G E_{2}$ production. It is not yet clear which of the prostanoid G-protein-coupled receptors is responsible for the observed effects. Endothelial COX-2 promotes integrin $\alpha v \beta 3$ mediated cell adhesion, migration and angiogenesis through the prostaglandin-cAMP-PKA-dependent activation of Rac and Cdc42. Recently, COX-2 has been implicated in upregulation of the lymphangiogenic cytokine VEGF-C in lung adenocarcinomas, via transactivation of erbB-2 and Src (Su 2004).

In colon cancer cell lines COX-2 expression correlates with metastatic potential. Cells at the invasive front of cancers express high levels of COX-2, EGFR, Met and $\beta$-catenin. Functional studies suggest that $P G E_{2}$ transactivates Met (in the presence of activated EGFR), increases nuclear accumulation of $\beta$ catenin and induces uPAR, resulting in enhanced invasive potential (Pai
2003). COX-2 also upregulates CD44 and MMP-2.

Selective COX-2 inhibitors such as NS-398 inhibit colon cancer cell migration, invasion and MMP production, xenograft growth and liver metastasis (Table 5) (Yao 2004). The involvement of COX-2 at multiple points in tumour invasion and angiogenesis suggests that well-tolerated inhibitors such as the NSAIDS, particularly if combined with other therapeutic agents, may provide a useful approach (Gately, 2003). Intervention may be particularly useful in cases where surgery is impractical - e.g. where multiple intestinal or bladder polyps exist and where there is a risk of progression to invasive cancer.

\section{Chemokines}

Chemokines interact with G-protein coupled receptors to mediate adhesion of leucocytes to endothelial cells and to induce cytoskeletal alterations and motility. They cooperate with other cell surface proteins to direct the "homing" of haematopoietic cells. Metastasising breast (and also prostate and ovarian) tumour cells may also adopt this process. High levels of CXCR4 (and CXCR7) chemokine receptors were found on metastatic breast carcinoma cells. In addition, the major CXCR4 and CXCR7 ligands (respectively CXCL12 and CCL21) were preferentially expressed in lymph nodes, lungs, liver, bone marrow; common sites of metastasis.

Signalling through CXCR4 mediates tumour cell chemotaxis and invasion and is inhibited by CXCR4 blocking antibodies, as is lung colonisation and metastasis of tumour xenografts. CXCR4 activation results in phosphorylation of $\mathrm{PI} 3$ kinase and multiple proteins involved in cell adhesion and motility (e.g. FAK, RAFTK/ Pyk2, paxillin, Crk, Cbl) and upregulation of MMP-2 and MMP-9 (Fernandis 2004).

Recently, it was found that the intestinal microvasculature expresses CXCR4, suggesting a key role in regulating angiogenesis within the gut (and therefore potentially within colorectal carcinomas). CXCL12 activates MAPK and PI3K pathways in human intestinal microvascular endothelial cells (HIMEC) through CXCR4 and induces their proliferation and chemotaxis. In vitro "angiogenesis" (tube formation) was inhibited by neutralising antibodies directed against the ligand or receptor (Heidemann 2004). Interestingly, hypoxia, mutations in the tumour suppressor gene VHL, (Schioppa 2003) and VEGF all upregulate expression of CXCR4. This may be another means by which the neoangiogenic environment induced by tumour hypoxia or misregulation of HIF$1 \alpha$ via loss of VHL potentiates invasion and metastasis.

The Glu-Leu-Arg (+) (ELR+) CXC chemokines, all of which bind to the receptor $\mathrm{CXCR} 2$, are potent inducers of angiogenesis. The development, vascular density and metastatic potential of Lewis lung carcinoma xenografts was significantly reduced in either CXCR2 -/- mice or CXCR2+/+ mice treated with blocking

\section{COX-2 INHIBITORS WITH ANTI-INVASIVE AND ANTI-ANGIOGENIC POTENTIAL}

\begin{tabular}{ll} 
Inhibitor & Effect \\
\hline JTE-522 & Inhibits VEGF production and liver metastasis of HT29 \\
NS-398 & Suppresses proliferation, invasion and liver metastasis and decreases MMP-2 and MMP-9 production by MC-26; inhibits sponge/matrigel angiogenesis \\
Aspirin and sodium salicylate & Inhibits endothelial tube formation in response to CM from DLD-1, HT29 and HCT-116 colon ca cells \\
SC236 + Iressa + AS-PKA & Inhibits COX-2, VEGF and FGF2 and > tumour growth and angiogenesis in vivo \\
Meloxicam, SC560 & Inhibits HGF-induced angiogenesis, primarily via effects on endothelial cell migration and invasion
\end{tabular}




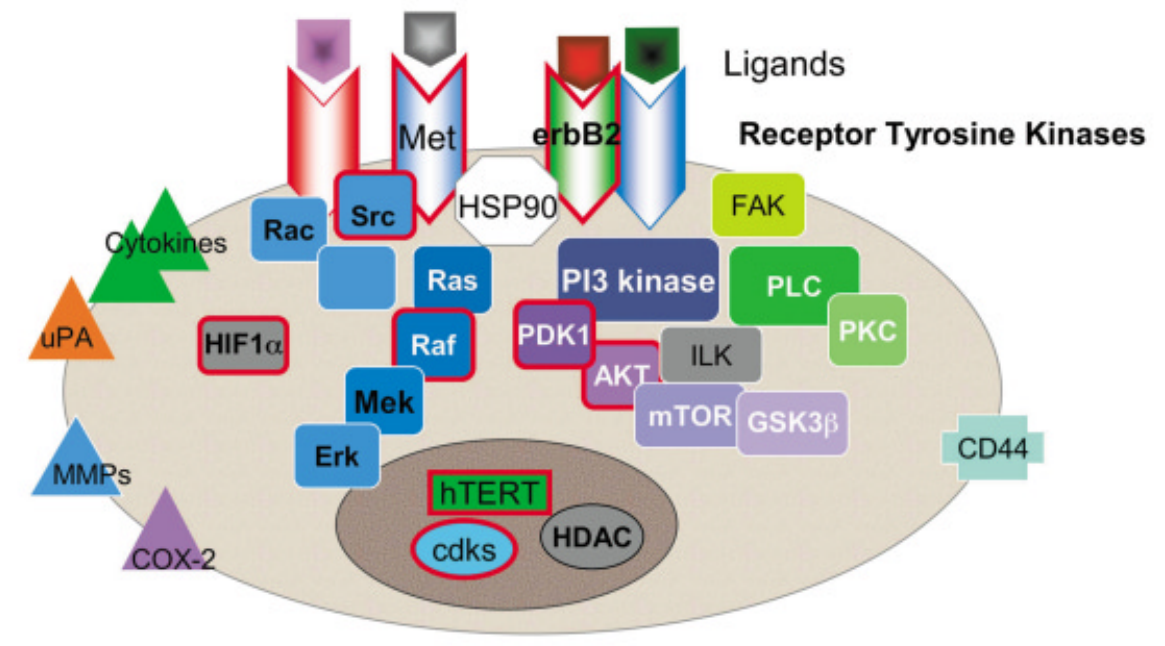

Fig. 6. Signalling circuits as targets for therapy. Signalling molecules downstream of receptor tyrosine kinases may provide pivotal points for therapeutic intervention. Compounds which inhibit these targets should affect not only cell proliferation, but also invasion and angiogenesis. It is likely that combinations of pathway inhibitors will be necessary to address the "multigene" phenotype of advanced cancers; or multitarget approaches such as provided by Hsp90- or bi-tri-kinase inhibitors. Hsp90 "client" proteins are shown with a red boundary. Signalling molecules are lozenge shaped, and bioactive molecules (cytokines, enzymes) are triangles. understand how best to balance specificity with the challenge of multigenic metastatic phenotypes and try to identify "pivotal points" for intervention. Promising initial targets include RTKs which activate multiple downstream signalling cascades, molecules such as PLC and PI3K which integrate messages from several upstream activators, or Hsp90 which is essential for the correct functioning of several key oncogenic effectors. A further challenge will be identifying the contribution of direct (antitumour) and indirect (anti-host) effects, since this may have implications for drug combinations and scheduling of therapy. Nevertheless, there is reason for optimism that a new generation of agents designed to inhibit key aspects of tumour progression may be advantageous. Inhibiting cell proliferation (the target of most "conventional" therapies) is a poor discriminator of malignancy and the cause of most dose-limiting toxicities. Agents designed to inhibit cell motility and invasion may give a better therapeutic window, the opportunity for targeting both tumour invasion and neoangiogenesis and effectively complement existing approaches. antibodies directed against the receptor (Keane 2004). This provides evidence for a direct role of this signalling pathway in lung metastasis. IL-8 (CXCL8) is also a ligand for CXCR2and induced similar responses to CXCL12 in HIMEC. A detailed survey of the roles of chemokines in angiogenesis has recently been published (Bernardini 2003)

These key observations indicate how a single ligand-receptor system might "attract" metastatic cells to specific sites and then potentiate their invasion. Antagonists of specific chemokine receptors could abort specific pathways of tumour cell dissemination, although in a "chemoprevention" setting. However, the finding that blocking CXCR4 function prevented lung and liver metastasis of CT-26 colon carcinoma cells not by inhibition of extravasation, but by outgrowth of established microcolonies may extend their utility (Zeelenberg, 2003). Interestingly, CXCR4 levels were strongly upregulated in vivoat sites of metastasis; hence disseminated cells may be more sensitive to inhibitors than predicted from in vitro assays. Also, since CXCR2 and CXCR4 are expressed on activated endothelial cells, such inhibitors may have a dual functionality. A small molecule inhibitor of CXCR4 (AMD 3100) has recently shown promise in the inhibition of intracranial growth of medulloblastoma and glioblastoma xenografts (Rubin 2003). Alternatively, transcriptional regulators of CXCR4 (such as NFKB) or effectors (such as PI3 kinase) may provide alternative targets.

\section{Summary}

It is clear that the molecular machinery of tumour cell invasion and neoangiogenesis share many common features. Several key components, including receptor tyrosine kinases, their downstream messengers and effector molecules such as proteases and cytokines provide a rich collection of potential therapeutic targets (Fig. 6). Some novel signalling inhibitors are already in the clinic. We need to

\section{References}

ABECASSIS, I., OLOFSSON, B., SCHMID, M., ZALCMAN, G. and KARNIGUIAN A, (2003) Rho A induces MMP-9 expression at CD44 lamellipodial focal complexes and promotes HMEC-1 cell invasion. Exp. Cell Res. 291:363-76

APTE, S.M., FAN.,D., KILLION, J.J. and FIDLER, I.J. (2004). Targeting the plateletderived growth factor receptor in antivascular therapy for human ovarian cancer. Clin. Cancer Res. 10: 897-908

BAUVOIS, B. (2004) Transmembrane proteases in cell growth and invasion: new contributors to angiogenesis? Oncogene 23: 317-29

BERNARDINI, G., RIBATTI, D., SPINETTI, G. et al. (2003). Analysis of the role of chemokines in angiogenesis. J. Immunol. Methods 273: 83-101

BIRCHMEIER, C., BIRCHMEIER, W., GHERARDI, E. and VANDE WOUDE, G.F (2003). Met, metastasis, motility and more. Nat. Rev. Molec. Cell Biol. 4: 91525

BOYD, D.D., WANG, H., AVILA, H. et al. (2004) combination of a SRC kinase inhibitor with a novel pharmacological antagonist of the urokinase receptor diminishes in vitro colon cancer invasiveness. Clin. Cancer Res. 10: 1545-55

BRADER, S. and ECCLES, SA. (2004) Phosphoinositide 3-kinase signaling pathways in tumor progression, invasion and angiogenesis. Tumori, 90: 3-9

BRANTLEY, D.M., CHENG, N., THOMPSON, E.J. et al. (2002) Soluble Eph receptors inhibit tumor angiogenesis and progression in vivo. Oncogene 21: 7011-26

CANDIA, P., SOLIT, D. B., GIRI, D., et al. (2003) Angiogenesis impairment in Iddeficient mice cooperates with an Hsp90 inhibitor to completely suppress HER2/neu-dependent breast tumors. Proc. Natl. Acad. Sci. USA100: 12337-42

CAVALLERO, U. and CHRISTOFORI, G. (2004) Cell adhesion and signalling by cadherins and Ig-CAMs in cancer. Nat. Rev. Cancer 4: 118-32

CHEN, J.X., LAWRENCE, M.L., CUNNINGHAM, G., CHRISTMAN, B.W. and MEYRICK, B. (2004). Hsp90 and Akt modulate Ang-1induced angiogenesis via NO in coronary artery endothelium. J. Appl. Physiol. 96: 612-20

COLLISSON, E.A., DE, A., SUZUKI, H., GAMBHIR S.S. and KOLODNEY, M.S. (2003). Treatment of metastatic melanoma with an orally available inhibitor of the Ras-Raf-MAPK cascade. Cancer Res. 63: 5669-73

DAVIES, G., MASON, M.D., MARTIN, T.A. et al. (2003). The HGF/SF antagonist NK4 reverses fibroblast- and HGF-induced prostate tumor growth and angiogenesis in vivo. Int. J. Cancer 106: 348-54 
De BOCK, C.E. and WANG, Y. (2004) Clinical significance of urokinase-type plasminogen activator receptor (UPAR) expression in cancer. Med. Res. Rev. 24: $13-39$

DEROANNE, C.F., BONJEAN, K., SERVOTTE, S. etal. (2002). Histone deactylase inhibitors as anti-angiogenic agents altering vascular endothelial growth factor signalling. Oncogene 21: 427-36

DKHISSI, F., LU, H., SORIA, C. et al. (2003) Endostatin exhibits a direct antitumour effect in addition to its antiangiogenic activity in colon cancer cells. Hum. Gene Ther. 14: 997-1008

DUMONT, N. and ARETEAGA, C.L. (2003) Targeting the TGF $\beta$ signalling network in human neoplasia. Cancer Cel/3: 531-6

ECCLES SA (2001) The role of c-erbB2/HER2/neu in breast cancer progression and metastasis In: J. Mammary Gland Biol. Neoplasia 6: 393-406

ECCLES, S.A., BRADER, S., COURT, W. et al. (2004) HSP90 inhibition targets endothelial cell functions and tumour neoangiogenesis. J. Chemother. 16: suppl $1 \mathrm{p} 123$

ECCLES, S., BRADER S, COURT, W, BOX, G. and WORKMAN P. (2003) Phospholipase $C$ is a key mediator of endothelial cell functions required for neoangiogenesis. Proc. Amer. Assoc. Cancer Res. (2 ${ }^{\text {nd }}$ Ed). 44: 2072

EASWARAN, V., LEE, S.H., INGE, L. et al. (2003) Beta catenin regulates vascular endothelial growth factor expression in colon cancer. Cancer Res. 63: 3145-53

FERNANDIS, A.F., PRASAD, A., BAND, H., KLOSEL, R. and GANJU, R.K. (2004) Regulation of CXCR4-mediated chemotaxis and chemoinvasion of breast cancer cells. Oncogene 23: 157-67

FRIEDL P. and BROCKER, E.B. (2000) The biology of cell locomotion within threedimensional extracellular matrix. Cell Mol. Life Sci. 57: 41-64

GABARRO-NIECKA, V., SCHALLER, J.M. and DUNTY, J.M. (2003) FAK regulates biological processes important for pathogenesis. Cancer Met. Rev22: 359-74

GATELY., S. and KERBEL, R. (2003) Therapeutic potential of selective COX-2 inhibitors in the management of tumor angiogenesis. Prog. Exp. Tum. Res 37: 179-92

GOETZ, M. P., TOFT, D. O., AMES, M. M. and ERLICHMAN, C. (2003) The Hsp90 chaperone complex as a novel target for cancer therapy. Annals Oncol., 14 1169-1176,

GOODWIN, A.M. and D'AMORE, P.A. (2002). Wnt signalling in the vasculature. Angiogenesis 5: 1-9

GUBA M., VON BREITENBUCH P., STEINBAUER M. et al., (2002) Rapamycin inhibits primary and metastatic tumor growth by antiangiogenesis: involvement of vascular endothelial growth factor. Nature Med, 8: 128-35

HASKELL, H., NATARAJAN, M., HECKER, T.P. et al. (2003). Focal adhesion kinase is expressed in the angiogenic blood vessels of malignant astrocytic tumors in vivo and promotes capillary tube formation of brain microvascular endothelial cells. Clin. Cancer Res. 9: 2157-65

HEIDEMANN, J., OGAWA, H., RAFIEE, P. et al. (2004). Mucosal angiogenesis regulation by CXCR4 and its ligand CXCL12 expressed by human intestinal microvascular endothelial cells. Am. J. Physiol. Gastrointest. Liver Physiol. 10.1152/ajpgi.00417 (epublication ahead of print).

HEIDER, K.H., KUTHAN, H., STEHLE, G. and MUNZERT, G.(2004) CD44v6: a target for antibody-based cancer therapy. Cancer Immunol. Immunother. Feb ruary 5 (e publication).

HOLBRO,T., CIVENNI, G. and HYNES, N.E. (2003) The ErbB receptors and their role in cancer progression. Exp. Cell Res. 284: 99-110

HURT, E.M., WIESTNER, A., ROSENWALD, A. et al. (2004) Overexpression of cmaf is a frequent oncogenic event in multiple myeloma that promotes proliferation and pathological interactions with bone marrow stroma. Cancer Ce//5: 191 9

INIGUEZ, M.A., RODRIGUEZ, A.M., VOLPERT, O.V., FRESNO, M. and REDONDO, J.M. (2003) Cycooxygenase-2: a therapeutic target in angiogenesis. Trends Molecular Med. 9: 73-8

JIN, H. and VARNER, J. (2004) Integrins: roles in cancer development and as treatment targets. Br. J. Cancer90: 561-5

JORISSEN, R.N., WALKER, F., POULIOT, N., GARRETT, T., WARD, C.W. and BURGESS, A.W. (2003). Epidermal growth factor receptor: mechanisms of activation and signalling. Exp. Cell. Res. 284: 31-53

KEANE, M.P., BELPERIO, J.A., XUE, Y.Y., BURDICK, M.D. and STRIETER, R.M.
(2004) Depletion of CXCR2 inhibits tumor growth and angiogenesis in a murine model of lung cancer. J. Immunol. 172: 2853-60

KILLARSKI, W.W., JURA, N. and GERWINS, P. (2003). Inactivation of Src family kinases inhibits angiogenesis in vivo: implications for a mechanism involving organisation of the actin cytoskeleton. Exp. Cell Res. 291: 70-82

KIM, E., GUNTHER, W., YOSHIZATO, K. et al. (2003). Tumor suppressor p53 inhibits transcriptional activation of invasion gene thromboxane synthase mediated by the proto-oncogenic factor ets-1. Oncogene 22: 7716-27

KIM, S.H., AHN, S., HAN, J.W. et al. (2004) Apicidin is a histone deacetylase inhibitor with anti-invasive and anti-angiogenic potentials. Biochem. Biophys. Res. Commun. 315: 964-70

KIM, S.J., JOHNSON, M., KOTERBA, K. et al. (2003). Reduced c-met expression by an adenovirus expressing c-met ribozyme inhibits tumorigenic growth and lymph node metastases of PC3-LN4 prostate tumor cells in an orthotopic nude mouse model. Clin. Cancer Res. 9: 5161-70

KITADAI, Y., SASAKI, A., ITO, M. et al. (2003) Helicobacter pylori infection influences expression of genes related to angiogenesis and invasion in human gastric carcinoma cells. Biochem. Biophys. Res. Commun. 311: 809-14

KRISHNAMACHARY B., BERG-DIXON, S., KELLY, B. et al,. (2003) Regulation of colon carcinoma cell invasion by hypoxia-inducible factor 1. Cancer Res. 63: 1138-43

KROL, J., SATO, S., RETTENBERGER, P. et al. (2003) Novel bi- and tri-functional inhibitors of tumor-associated proteolytic systems. J. Biol Chem. 384: 1085-96

KUMAR, P., AMIN, M.A., HARLOW, L.A., POLVERINI, P.J. and KOCH, A.E. (2003). Src and phosphatidyl 3-kinase mediate soluble E-selectin-induced angiogenesis. Blood 101: 3960-8

KUREBAYASHI, J., OTSUKI, T., KUROSUMI, M. etal. (2001) A radicicol derivative, KF58333, inhibits expression of hypoxia-inducible factor-1alpha and vascular endothelial growth factor, angiogenesis and growth of human breast cancer xenografts. Jpn. J. Cancer Res. 92: 1342-51

LAKKA, S.S., GONDI, C.S., YANAMANDRA, N. et al. (2003) Synergistic downregulation of urokinase plasminogen activator receptor and MMP-9 in SNB19 glioblastoma cells efficiently inhibits glioma cell invasion, angiogenesis and tumor growth. Cancer Res. 63: 2454-61

LEE, L.F., LOUIE, M.C., DESAI, S.J. et al. (2004) Interleukin 8 confers androgenindependent growth and migration of LNCaP: differential effects of tyrosine kinases Srk and FAK. Oncogene 23: (online prepublication Feb 9)

LIN, M.T., YEN, M.L., LIN, C.Y. and KUO, M.L. (2003) Inhibition of vascular endothelial growth factor-induced angiogenesis by resversatrol through interruption of Src-dependent vascular endothelial cadherin tyrosine phosphorylation. Mol. Pharmacol. 64: 1029-36

MA, P.C., MAULIK, G., CHRISTENSEN, J. and SALGIA, R. (2003) c-MET: structure, functions and potential for therapeutic inhibition. Cancer Met. Rev 22: $309-25$

MALONEY, A. and WORKMAN, P. (2002) Hsp90 as a new therapeutic target for cancer: the story unfolds. Expert Opin. Biol. Ther. 2:3-24,

MAHABELESHWAR, G.H. and KUNDU, G.C. (2003). Tyrosine kinase p56 lck regulates cell motility and nuclear factor $\kappa B$-mediated secretion of urokinase type plasminogen activator through tyrosine phosphorylation of $\mathrm{I} \mathrm{KB} \alpha$ following hypoxia/reoxygenation. J. Biol. Chem. 278: 52598-612

MANETTI, F. and BOTTA, M. (2003). Small molecule inhibitors of fibroblast growth factor receptor (FGFR) tyrosine kinases (TK). Curr. Pharm. Des. 9: 567-81

MANIOTIS A.J., FOLBERG, R., HESS A. et al. (1999) Vascular channel formation by human melanoma cells in vivo and in vitro: vasculogenic mimicry. $A m \mathrm{~J}$ Pathol, 155: 739-52

MAREEL, M. and LEROY, A. (2003). Clinical, cellular and molecular aspects of cancer invasion. Physiol. Rev. 83: 337-76

MAZURE, MM., BRAHIMI-HORN, M.C. and POUYSSEGUR, J. (2003) Protein kinases and the hypoxia-inducible factor-1, two switches in angiogenesis. Curr. Pharm. Design 9: 531-41

MENDELSOHN, J. and BASELGA, J. (2003) status of epidermal growth factor receptor antagonists in the biology and treatment of cancer. J. Clin. Oncol. 14: 2787-99

NAKAJIMA, M., HAYASHI, K., KATAYAMA, K. et al. (2003) Wf-536 prevents tumor metastasis by inhibiting both tumor motility and angiogenic actions. Eur. J. Pharmacol. 459: 113-20 
NEMETH, J.A., CHER, M.L. ZHOU, Z. et al. (2003) Inhibition of $\alpha v \beta 3$ integrin reduces angiogenesis, bone turnover and tumor cell proliferation in experimental prostate cancer bone metastases. Clin. Exp. Metastasis 20: 413-20

NISHIHIRA, J., ISHIBASHI, T., FUKUSHIMA, T, SUN, B., SATO, Y., TODO, S. (2003) Macrophage migration inhibitory factor (MIF): its potential role in tumor growth and tumor associated angiogenesis. Ann. N.Y. Acad. Sci. USA 995: 171-82

O-CHAROENRAT, P., RHYS-EVANS, P., MODJTAHEDI, H.and ECCLESS.A. (2000) Vascular endothelial growth factor family members are differentially regulated by c-erbB signaling in head and neck squamous carcinoma cells. Clin. Exp. Metastasis 18: 155-161

O-CHAROENRAT, P.,, RHYS-EVANS, P.H., ARCHERD.J. and ECCLESS.A. (2002a) c-erbB receptors in squamous cell carcinomas of the head and neck: clinical significance and correlation with matrix metalloproteinases and vascular endothelial growth factors. Oral Oncol. 38: 73-80

O-CHAROENRAT, P., RHYS-EVANS, P. and ECCLES, S.A. (2002b) A synthetic matrix-metalloproteinase inhibitor prevents squamous carcinoma cell proliferation by interfering with epidermal growth factor receptor autocrine loops. Int. J. Cancer 100: 527-33

OLIVEIRA M.J., VAN DAMME, J., LAUWAET, T. et al. (2003) Beta-casein-derived peptides, produced by bacteria, stimulate cancer cell invasion and motility. $E M B O$ J. 22: 6161-73

PAI, R., NAKAMURA, T., MOON, W.S. and TARNAWSKI, A.S. (2003) Prostaglandins promote colon cancer cell invasion; signalling by cross-talk between two distinct growth factor receptors FASEB J. 17: 1640-7

PENNACCHIETTI, S., MICHIELI, P. and GALLUZZO,M. et al. (2003). Hypoxia promotes invasive growth by transcriptional activation of the metprotoncogene. Cancer Cel/3: 347-61

PLE, P.A., GREEN, T.P., HENNEQUIN, L.F. et al. (2004) Discovery of a new class of anilinoquinazoline inhibitors with a high affinity and specificity for the tyrosine kinase domain of C-src. J. Med. Chem. 47: 871-87

RAKIC, J, N., GERBER, H-P and LECOUTER, J. (2003a) The biology of VEGF and its receptors. Nature Med. 6:669-76

RAKIC, J. M., MAILLARD, C., JOST, M. et al. (2003b) Role of plasminogen activatorplasmin system in tumor angiogenesis. Cell Mol. Life Sci., 60:463-73.

RAFTOPOULOU, M. and HALL, A. (2004) Cell migration: Rho GTPases lead the way. Dev. Biol. 265: 23-32

RAPISARDA, A., URANCHIMEG, B., SCUDIERO, D.A. et al. (2002) Identification of small molecule inhibitors of hypoxia-inducible factor 1 transcriptional activation pathway. Cancer Res. 62: 4316-24

RECCHIA, I., RUCCI, N., FESTUCCIA, C. et al. (2003) Pyrrolopyrimidine c-Src inhibitors reduce growth, adhesion, motility and invasion of prostate cancer cells in vitro. Eur. J. Cancer39: 1927-35

REDDY, K.B., NABHA, S.M. and ATANASKOVA, N. (2003). Role of MAP kinase in tumor progression and invasion. Cancer Met. Rev. 22: 395-403

RUBIN, J.B., KUNG, A.L., KLEIN, R.S. et al. (2003) A small molecule antagonist of CXCR4 inhibits intracranial growth of primary brain tumours. Proc. Natl. Acad. SCI USA. 100: 13513-18

RUEGG, C., DORMOND, O. and MARIOTTI, A. (2004) Endothelial cell integrins and COX-2: mediators and therapeutic targets of tumor angiogenesis. Biochem Biophys Acta 1654: 51-67

SANZ, L.and ALVAREZ-VALLINA, L., (2003). The extracellular matrix: a new turn of the screw for antiangiogenic strategies. Trends. Molec. Med. 9: 256-62

SASAKAWA, Y., NAOE, Y., NOTO, T. et al. (2003) Antitumor activity of FK228, a novel histone deacetylase inhibitor depends on the effect on expression of angiogenesis factors. Biochem. Pharmacol. 66: 897-906

SEMENZA G.L. (2003) Targeting HIF-1 for cancer therapy. Nat. Rev. Cancer3: 721-32

SENGUPTA, S., SELLERSL. A., CINDROVA, T. et al. (2003) Cycooxygenase-2selective non-steroidal anti-inflammatory drugs inhibit hepatocyte growth factor/ scatter factor induced angiogenesis. Cancer Res. 63: 8351-9

SCHAEFFER, J.S. and ZHANG, M. (2003) Role of maspin in tumor metastasis and angiogenesis. Curr. Mol. Med. 3: 653-8

SCHIOPPA, T., URANCHIMEG, B., SACCANI, A. et al. (2003) The hypoxic tumour environment and metastatic progression. Clin. Exp. Metastasis. 20: 237-50

SEIKI, M., MORI, H., KAJITA, M., TAKAMASA, U. and ITOH, Y. (2003). Membranetype 1 matrix metalloproteinases and cell migration. Biochem. Soc. Symp. 70: 253-62
SHAKESPEAR, WC, METCALF, CA, WANG, Y. et al. (2003). Novel bone-targeted Src tyrosine kinase inhibitor drug discovery. Curr. Opin. Drug Discov. Devel. 6: 729-41

SIDENIUS, N. and BLASI, F. (2003) The urokinase plasminogen activator system in cancer: recent advances and implication for prognosis and therapy. Cancer Met. Rev. 22: 205-22

SHIMAOKA, M. and SPRINGER, T.A. (2003). Therapeutic antagonists and conformational regulation of integrin function. Nat. Rev. Drug Discovery2: 703-715

SOARESR, GUOS., GARTNER F., SCHMIDT FC and RUSSOJ. (2004) 17 -estradiolmediated vessel assembly and stabilization in tumor angiogenesis requires TGF $\beta$ and EGFR crosstalk. Angiogenesis. Vol 7 epublication ahead of print

STUPACK, D.G. and CHERESH, D.A. (2003) Apoptotic cues from the extracellular matrix: regulators of angiogenesis. Oncogene 22: $9022-29$

STURGE, J., WIENKE, D., EAST, L., JONES, G.E. and ISACKE, C.M (2003). GPIanchored uPAR requires Endo 180 for rapid directional sensing during chemotaxis. J. Cell Bio/162: 789-94

SU, J.L., SHIH, J.Y., YEN, M.L. etal. (2004) Cyclooxygenase-2 induces EP1 and HER2/Neu-dependent vascular endothelial growth factor $C$ upregulation: a novel mechanism of lymphangiogenesis in lung adenocarcinoma. Cancer Res. 64: 554-64

SUBARSKY, P. and HILL, R.P. (2003) The hypoxic tumour environment and metastatic progression. Clin. Exp. Metastasis 20:237-50

SUDHAKER, A., SUGIMOTO, H., YANG, C. et al. (2003) Human tumstatin and human endostatin exhibit distinct antiangiogenic activities mediated by alpha $\mathrm{v}$ beat 3 and alpha 5 beta 1 integrins. Proc. Natl. Acad. Sci. USA 100: 4766-71

SUMMY, J.M. and GALLICK, G.E. (2003). Src family kinases in tumor progression and metastasis. Cancer. Met. Rev. 22: 337-58

TAKAHASHI Y., ELLIS L.M. and MAI, M. (2003) The angiogenic switch of human colon cancer occurs simultaneously to initiation of invasion. Oncol. Rep. 10: 9-13

TAN, C., CRUET-HENNEQUART, S., TROUSSARD, A. et al. (2004) Regulation of tumor angiogenesis by integrin-linked kinase (ILK). Cancer Ce//5: 79-90

TORTORA, G., CAPUTO, R., DAMIANO, V. et al. (2003) Combination of a selective cyclooxygenase-2 inhibitor with ZD1839 and a protein kinase A antisense causes cooperative antitumour and antiangiogenic effect. Clin. Cancer Res. 9: 1566-72

TUCKER, G.C. (2003) $\alpha$ v integrin inhibitors and cancer therapy. Curr. Opin. Invest. Drugs. 4: $722-31$

VASSILEV, L.T., VU. B.T., GRAVES, B. et al. (2004). In vivo activation of the p53 pathway by small molecule antagonists of MDM2. Science 303: 844-8

VINDIS, C., CERRETTI, D.P., DANIEL, T.O. and HUYNH-DO, U. (2003). EphB1 recruits c-Src and p52Shc to activate MAPK/ERK and promote chemotaxis. J. Cell Biol. 162: 661-71

VLODAVSKY, I., GOLDSCHMIDT, O., ZCHARIA, E. et al. (2002). Mammalian heparanase: involvement in cancer metastasis, angiogenesis and normal development. Semin. Cancer Biol. 12: 121-9

WANG, X., LE, P., LIANG, C. et al. (2003) Potent and selective inhibitors of the met [hepatocyte growth factor/scatter factor (HGF/SF) receptor tyrosine kinase] block HGF/SF induced tumour cell growth and invasion. Mol. Cancer Ther. 2: 1085-92

WEBB, C.P. HOSE, C.D., KOOCHEKPOUR, S. et al. (2000) The geldanamycins are potent inhibitors of the hepatocyte growth factor/scatter factor-met-urokinaseplasminogen activator-plasmin proteolytic network. Cancer Res. 60: 342-9

WELLS, A.and GRANDIS, J. (2003) Phospholipase C-gamma1 in tumor progression. Clin. Exp. Metastasis, 20:285-90.

YANG, Y., DUKHANINA, O., TANG., B., MAMURA,M. et al. (2002). Lifetime exposure to a soluble TGF- $\beta$ antagonist protects mice against metastasis without adverse side effects. J. Clin. Invest. 109: 1607-1615

YAO, M., LAM, E.C., KELLY, C.R., ZHOU, W. and WOLFE, M.M. (2004). Cycooxygenase2 selective inhibition with NS-398 suppresses proliferation and invasiveness and delays liver metastasis in colorectal cancer. Br. J. Cancer90: 712-9

YEO, E.J., CHUN, Y-S., CHO, Y-S. et al. (2003) YC-1: a potential anticancer drug targeting hypoxia-inducible factor1. J. Natl. Cancer. Inst. 95: 516-25.

ZEELENBERG, I.S., RUULS-VAN STALLE, L. and ROOS, E. (2003). The chemokine receptor CXCR4 is required for outgrowth of colon carcinoma micrometastases. Cancer Res. 63: 3833-9

ZHANG, D., SAMANI, A.A. and BRODT, P. (2003) The role of the IGF-1 receptor in the regulation of matrix metalloproteinases, tumor invasion and metastasis. Horm. Metab. Res. 35: 802-8 